\title{
ISSN 2317-3009
}

\section{Archives of Health Investigation}

Official Journal of the

II COMFER

II Congresso Médico de Fernandópolis

Universidade Brasil

Curso de Medicina - Campus Fernandópolis

2021 


\title{
UG U UNIVERSIDADE BRASIL
}

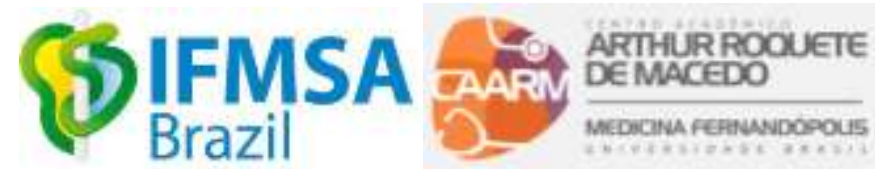

II COMFER - CONGRESSO MÉDICO DE FERNANDÓPOLIS

\author{
DISCENTES \\ Presidente do II COMFER \\ Vinícius Paiva Gontijo \\ Suporte Plataforma
}

Monic Rondina Fontes Tathiane Francisco Afves

Departamento de Imprensa e Mídias Sociais

Amanda Pinato Alves da Costa Isabela Harumi Gomi

Emanoel de Oliveira Araujo Marilia Sant'Ana Sequini

Paloma Tonani

Suporte /Contato Palestrantes

Eduarda Andrea Pessuto Gonçalves Guilherme Trojillo Gil

Pedro Augusto Izidoro Pereira

Departamento Social

Leonardo Ferreira Santana Maressa Maziero de Carvalho

Departamento de Patrocinadores

Leonardo Ferreira Santana Paloma Tonani

Vinicius Lis6oa da Rocha

Suporte Geral e Apresentação do Evento

João Jorge Bizio $\mathcal{N}$ eto Emanoel de Oliveira Araujo

Vinicius Lisboa da Rocha

\section{DOCENTES \\ Comissão Científica}

Prof. Dr. José Martins Pinto Neto

Prof. Dr. Leandro Teixeira Paranhos Lopes

Prof. Dra. Alba Regina Abreu Lima

Prof. Esp. Fábio Carniello Duarte e Silva

Prof. Me. André Willian Lozano

Prof. Me. Márcio Cesar Reino Gaggini

Profa. Dra. Daniela Regino Garcia

Profa. Dra. Elizabete Melo Montanari Fedocci

Profa. Dra. Luciana Estevam Simonato

Profa. Dra. Patrícia Michelassi Carrinho Aureliano

Profa. Ma. Priscila Cristina Oliveira Zignani Pimentel

Banca Examinadora

Prof. Dra. Alba Regina Abreu Lima

Prof. Dr. Luiz Flávio Franqueiro

Prof. Dr. José Martins Pinto Neto 


\section{UB) UNIVERSIDADE}
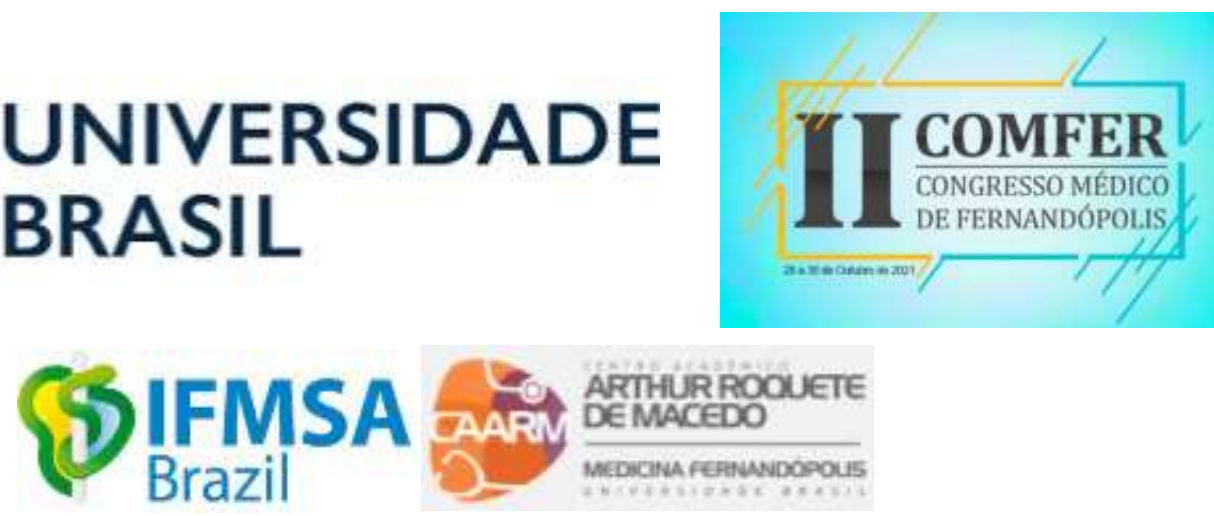

\section{Pragramaçãa}

A Medicina Fernandópolis tem a honra de mais uma vez realizar o Congresso Médico de Fernandópolis (COMFER). Neste ano, $\sigma$ Curso de Medicina da Universidade Brasil - Campus Fernandópolis vivenciará, no periodo de 28 a 30 de outubro de 2021, $\sigma$ II Congresso Médico de Fernandópolis (II COMFER). Mesmo com adversidades ocasionadas pela pandemia, acreditamos que $\sigma$ ensino de qualidade, a vivência de profissionais de excelência em cada área e a troca de conhecimento entre docentes e discentes não poderiam ser prejudicadas. Mediante a isso, depois do grande sucesso do evento em 2020, reatizaremos $\sigma$ II COMFER na modalidade online em 2021.

$\mathcal{O}$ nosso congresso traz em sua grade cientifica uma abordagem do mais alto nivel, apresentando palestras ministradas por profissionais da área médica do mais alto renome, além dos trabalhos, para apresentação painel e oral que será escolhido dentre of 10 melhores trabalhos, nas modalidades Pesquisa Cientifica, Caso Clínico, Revisão de Literatura e Projeto de Extensão Universitáría.

As palestras serão ministradas por renomados expoentes da Medicina, sempre embasados no que há de mais atual em termos de pesquisa científica. Serão abordados temas relevantes sobre saide voltados para a prática clínica, transmitindo e gerando conhecimentos aos participantes deste evento e, desta forma, atingindo e proporcionando beneficios à população.

Como novidade, neste ano abriremos a oportunidade para outras áreas da sauide e para acadêmicos de direito que queiram submeter e apresentar trabalhos que estejam em consonância com a medicina. Uma grande oportunidade se abrírá para que profissionais e acadêmicos de outras áreas da sauide possam trocar conhecimentos, sempre em busca do melhor resultado ao paciente. Aproveitem ao máximo o evento que foi preparado no mais alto nivel e estejam atentos a cada palestra que será apresentada no II COMFER.

Sejam todos muito bem vindos! Obrigado!

Vinicius Paiva Gontijo

Presidente Discente do II Congresso Médico de Fernandópolis Curso de Medicina da Universidade Brasil - Campus Fernandópolis 


\section{Editarial}

Caro(a) Leitor(a),

O II Congresso Médico de Fernandópolis (II COMFER) da Universidade Brasil. Campus Fernandópolis, realizado nos dias 28 a 30 de outubro de 2021, mostrou-se um sucesso. Contamos com a participação de 9 profissionais médicos, que transmitiram através de palestras, un conhecimento de alta qualidade para os participantes.

Neste ano, com o intuito de continuar levando conhecimento técnico $e$ cientifico para acadêmicos e profissionais de diversas áreas da saide, o evento propôs uma experiência diferente, de forma ontine, prezando a segurança de todos devido a pandemia da COVID19. Contamos com palestrantes egressos do Curso de Medicina de Fernandópolis, convidados de várias especialidades médicas, oriundos de outras instituições tais como: Universidade Estadual Paulista Júlio de Mesquita Filho (UNESP); Universidade Camilo Castelo Branco (UNICASTELO); Faculdade de Medicina de São José do Rio Preto (FAMERP); Faculdade de Medicina da Universidade de São Paulo (FMUSP); Faculdade de Medicina de Rúbeirão Preto da Universidade de São Paulo (FMRP-USP); Pontifícia Universidade Católica de Goiás (PUC-GO); Universidade Federal de São Paulo - Escola Paulista de Medicina (UNIFESP-EPM) e Faculdade de Medicina de Catanduva (FAMECA).

$\mathcal{O}$ evento contow com a presença de 240 congressistas, entre eles, alunos do Curso de Medicina da Universidade Brasil em Fernandópolis e outras instituiçöes de ensino do Brasil; médicos residentes na cidade de Fernandópolis e médicos residentes na região. Com inovação e tecnologia, neste ano abrimos a oportunidade à vários profissionais da saide do Brasil e de outras áreas como o Direito Médico, a fím de acompanhar o congresso e submeter trabalhos cientificos que tivessem uma temática em consonância à medicina.

Contamos com 65 painéis submetidos nas modalidades: Pesquisa Cientifica, Caso Clínico, Revisão de Literatura e Projeto de Extensão Universitáría. Dentre as submissões, foram escothidos os 10 melhores para apresentaçã oral, realizada no dia 30 de outubro.

Diante do sucesso alcançado, gostariamos de agradecer a todos os envolvidos na realização deste evento. Nossos sinceros agradecimentos aos 18 membros da Comissão Organizadora, dentre discentes e docentes que com muito empenho puderam realizar este evento que só tende a abrithantar o Curso de Medicina da Universidade Brasil (UB), sempre com o intuito de levar conhecimento e vivêncía na área da saíde. Muito obrigado a UB e a IFMSA BRAZIL - UB pelo apoio para realização do II COMFER.

Em 2022 estaremos de volta!

Vinicius Paiva Gontijo

Presidente Discente do II Congresso Médico de Fernandópolis Curso de Medicina da Universidade Brasil - Campus Fernandópolis 
28 a 30 de outubro de 2021 Curso de Medicina - Campus Fernandópolis

Universidade Brasil

DOI: http://doi.org/10.21270/archiv111.5693

\section{Resumas das}

\section{Trabalhas Apresentadas}

Atenção: Os conteúdos apresentados a seguir bem como a redação empregada para expressá-los são de inteira responsabilidade de seus autores. O texto final de cada resumo está aqui apresentado da mesma forma com que foi submetido pelos autores. 


\section{A ASSISTÊNCIA PRÉ-NATAL NO SUS: ANÁLISE DE ESTUDOS SOBRE A HUMANIZAÇÃO E A QUESTÃO RACIAL}

Isabella Manhoni Lima; Leonice Domingos dos Santos Cintra Lima(orientadora)

Categoria: Painel

Introdução: A qualidade do nascimento de um ser humano é essencial para definir sua qualificação de vida e bem-estar no futuro. A assistência de saúde ofertada a uma gestante no pré-natal, puerpério e até nos primeiros anos do desenvolvimento infantil é fundamental para promover, como consequência, boas condições de saúde para a mãe e para o neonato. No entanto, essa assistência pré-natal no SUS ainda encontra barreiras para atingir um atendimento pleno e integral em razão da falta de humanização ao se tratar de mulheres negras, a qual está relacionada ao velado preconceito étnico-racial persistente na sociedade brasileira. Objetivo: Analisar relação entre a assistência prénatal do SUS e a humanização no atendimento de mulheres negras. Trata-se de um estudo em curso do Programa de Iniciação Científica da Universidade Brasil. Materiais e Métodos: É uma pesquisa assentada em revisão de literatura e estudo do estado da arte, de caráter teórico descritivo, com busca em fontes secundárias, a partir de levantamento de artigos em bases científicas como Scielo, BVS, CAPES, PubMed; sites oficiais do Governo Federal, IBGE e ABRASCO. Foram selecionados somente artigos em português, publicados a partir de 2016. Resultados Parciais: Os estudos encontrados revelam uma forte ligação entre a cor negra com uma oferta deficiente e inadequada de assistência médica em gestantes usuárias do SUS, apontada pelas altas taxas de mortalidade materna negra em diversos estados do Brasil, com prevalência na região nordeste, onde, segundo IBGE, há 5,7 maior risco relativo de morte em relação às brancas. Estes fatos, segundo achados até o momento, podem estar relacionados à ocorrência de certas situações que colocam em risco a vida e a saúde da mãe e do bebê. Espera-se, com essa pesquisa, demonstrar a importância da atenção qualificada, igualitária e equânime a todas as mulheres no atendimento pré-natal, rompendo, desta forma, os paradigmas que compõe essa questão racial. Conclusão Parcial: As raízes do preconceito racial, intrínsecas à sociedade brasileira também interferem e se refletem intensa e amplamente na saúde pública, podendo ser danosas quando observadas sob o ângulo da atenção à saúde maternoinfantil da população negra.

Descritores: Desigualdade Racial em Saúde. Assistência Pré-Natal. Saúde da Mulher. 


\section{A COMPLEXA RELAÇÃO ENTRE A RELIGIOSIDADE E AS INTERFACES COM A MEDICINA}

Taiana Silva Ramos; Joana de Ângelis Ponte e Silva; Renata Tatiane Mendes Borges; Shirlei Cardoso de Almeida Santana; Marli dos Santos Roma Moretti; Keyla Talliari (orientadora)

Categoria: Painel

Introdução: A Organização Mundial da Saúde define saúde não apenas como ausência de doença, mas o estado do mais completo bem-estar físico, mental e social. Assim, uma visão correta exigiria a compreensão de saúde como uma situação dinâmica que implica a inclusão de procedimentos complexos, para cuidar do paciente e não só curar. Essa associação possui raízes históricas e durante a maior parte da história da humanidade, a magia, a religião e a cura quase sempre andaram juntas. Estudos vêm sido desenvolvidos relacionados a espiritualidade com o enfrentamento de doenças, promoção e reabilitação. Objetivo: demonstrar a complexa relação entre a religiosidade e as interfaces com a Medicina por meio de uma revisão de literatura. Material e Método: O presente estudo utilizou artigos da base de dados: BVS, Scielo, Lilacs, Google Acadêmico, PubMed dos anos 1998 até 2019, com base nas palavras chaves: "religiosidade", "espiritualidade", "medicina", "saúde", "doença". Foram incluídos os artigos que eram revisões de literatura com metanálise, estudos randomizados, sendo excluídos aqueles artigos que continham só resumo ou não estavam de acordo com o tema analisado. Resultados: A religião é considerada um termo muito amplo e complexo, visto como tradições estabelecidas por comunidades quanto às práticas e crenças acerca do sagrado. Já a espiritualidade está associada à busca independente pelo sagrado, sem amarras religiosas, fanatismos. Para a Medicina ver o paciente como um ser biopsicossocial, é necessário que haja um atendimento integral, que não vise apenas os aspectos físicos dos pacientes, mas que a saúde mental e as crenças sejam vistas e tenham importância no tratamento dos mesmos. Conclusão: Concluiu-se que as dificuldades perante a esse assunto poderiam estar associadas ao modelo biomédico, que não valoriza a dimensão cultural e tem predominado na formação médica. Dessa, maneira, é possível discutir e elaborar coletivamente as questões levantadas nos discursos produzidos nesta pesquisa, pois os conhecimentos advindos dos estudos poderão servir de referência para todos os que atuam na esfera médica.

Descritores: Espiritualidade. Medicina. Saúde. Doença 


\begin{abstract}
A IMPORTÂNCIA DA RADIOLOGIA NO SISTEMA ÚNICO DE SAÚDE
Janayne Fernandes da Silva, José Miguel de Souza Maia, Mariana Caroline Carocia, Nathália Regina Gasparelli Herrero Zinezi Rodrigues, Otávio Mendes Amêndola. Lucas Coimbra da Cruz (orientador)

Categoria: Painel
\end{abstract}

Introdução: Até o final do século XIX, a única forma de visualizar o interior do corpo humano era através de incisões, geralmente em cadáveres. A descoberta da radiologia impactou a vida dos pacientes e dos médicos. A radiologia é o campo da medicina que se dedica ao estudo e emprego dos raios $X$ e de outras energias radiantes, com fins diagnósticos e terapêuticos. A tecnologia de diagnóstico por imagem aos poucos foi se difundindo e hoje ocupa grande importância no Sistema Único de Saúde (SUS), isso porque, os resultados rápidos dos exames direcionam as condutas médicas e, inclusive, a radiologia pode ser utilizada como recurso de tratamento para doenças, como, por exemplo, o câncer. Objetivo: Revisar a literatura cientifica em relação à importância da radiologia no Sistema Único de Saúde. Metodologia: A metodologia empregada é de caráter analítico por meio de uma revisão de literatura bibliográfica. Os dados extraídos na pesquisa foram a partir dos US National Library of Medicine (PubMed) de acordo com os Descritores em Ciências da Saúde (DeCS). Para efetuar o cruzamento destes foi utilizado o operador booleano AND. Foram utilizados para a inclusão: artigos em inglês e/ou português, entre 2009 a 2021, e que estivessem disponíveis na íntegra e para acesso online grátis. Resultado: É irrefutável a importância da radiologia no SUS, entretanto, a grande problematização consiste no fato de o médico radiologista atuar num campo que utiliza um parque tecnológico com equipamentos modernos, de alto custo e de renovação intensa em software e hardware. Entretanto, o SUS é muito desigual nas regiões brasileiras, de forma que, em determinadas localidades, principalmente Sul e Sudeste do Brasil, grande parte dos hospitais contam com a disponibilidade para realização de raio $X$, tomografia computadorizada, ressonância magnética, dentre outros diagnósticos por imagens, enquanto que outras regiões carecem de recursos básicos como a própria presença do médico no serviço de saúde. Conclusão: A radiologia exerce papel notável e insubstituível no SUS, abrangendo diversas áreas de atuação como: raios $\mathrm{X}$, tomografia computadorizada, mamografia, densitometria óssea, ressonância magnética, medicina nuclear, radiologia industrial, radiologia odontológica, dentre outras. Assim, garantida a importância da radiologia, faz-se necessário melhorias na gestão do SUS para ampliar o acesso desses serviços de imagens para todos os usuários do sistema.

Descritores: Radiologia. Sistema Único de Saúde. Diagnóstico por Imagem 
28 a 30 de outubro de 2021 Curso de Medicina - Campus Fernandópolis Universidade Brasil

\section{A IMPORTÂNCIA DA VISITA DOMICILIÁRIA NA ATENÇÃO PRIMÁRIA À SAÚDE: UMA REVISÃO DE LITERATURA.}

Vanessa Balieiro dos Santos; Ana Carolina de Carvalho Gonçalves; Helena Cristina Alves Borges; Isabella Manhoni Lima; Flávio Carlos Ruy Ferreira (Orientador)

Categoria: Painel

Introdução: A visita domiciliária na circunstância da atenção básica acontece a partir da territorialização. As equipes atuam em uma área delimitada, empregando diversas alternativas de abordagem da família. A partir de características socioeconômica e estruturais do território delimitado, viabiliza que a equipe de $A B$ conheça o perfil da população e identifique as vulnerabilidades. Objetivos: $O$ presente trabalho tem como objetivo ressaltar a importância da visita domiciliária na Atenção Primária à Saúde e seus efeitos positivos no acompanhamento de usuários e famílias ao aplicar um cuidado integral e reconhecer o contexto em que esses usuários vivem. Metodologia: Foi realizada uma pesquisa bibliográfica de revisão de literatura, sendo feita a busca nas bases de dados eletrônicas Biblioteca Virtual em Saúde, Scielo e PubMed, sendo o critério de seleção utilizado os textos com as palavras "Visita Domiciliária" e "Atenção Primária à Saúde". Foram coletados 18 artigos escritos no idioma português, completos, contemplando o período de 2009 a 2021. Resultado: A visita domiciliária concretizou e ampliou o conceito de saúde integral na assistência primária através do envolvimento de equipes multidisciplinares. Sendo assim, possibilita maior interação entre as famílias e profissionais de saúde, gerando maior adesão ao tratamento, consolidando uma boa relação interpessoal e desenvolvendo ações educativas na comunidade visitada. Conclusão: A elaboração das visitas domiciliares é feita por um processo de planejamento sistematizado e respeitoso aos direitos dos cidadãos, sendo disposta como instrumento de alta potência para o trabalho compartilhado entre toda a equipe no serviço da atenção básica, contribuindo para a aproximação da realidade dos usuários e familiares na formação do vínculo.

Descritores: Saúde da Família. Atendimento Domiciliar, Cuidados Primários de Saúde. 


\section{ADMINISTRAÇÃO DE FLUÍDOS EM PACIENTES COM SEPSE}

Luana Martins Camilo, Micaelly Silva de Camargo, Mylena Aparecida Silva de Camargo, Natália Inácio Beltramini, Raissa Silva Frota, Amanda Oliva Spaziani (orientadora)

Categoria: Painel

Introdução: Sepse é uma síndrome de resposta inflamatória associada a infecção sistêmica. É uma doença heterogênea de ampla variação clínica. Tem alta incidência, letalidade e custos. É a principal causa de morte em unidades de terapia intensiva. $O$ tratamento inclui ampla abordagem com ênfase na reposição volêmica, que demostra um melhor prognóstico. Objetivos: Realizar uma revisão sistemática acerca da administração de fluidos em pacientes com sepse. Métodos: Trata-se de uma revisão bibliográfica de caráter analítico realizada por pesquisas nas bases de dados SciELO e Google Acadêmico por meio das palavras-chaves: "reposição volêmica", "sepse" e "tratamento". Foram encontrados 80 artigos e após critérios de inclusão e exclusão, 20 artigos foram selecionados. Os critérios para inclusão foram: artigos em português e inglês, entre 1998 e 2021, disponíveis na íntegra, gratuito e online. E os critérios de exclusão foram artigos que não abordassem o tema e estudos repetidos. Resultados: Sepse é uma síndrome de resposta inflamatória sistêmica desencadeada por infecções. Principal causa de morte nas UTIs. Pacientes tratados de forma precoce possuem melhor prognóstico. A Surviving Sepsis Campaign, tem o objetivo de reduzir a mortalidade em $25 \%$ em 5 anos, estabelecendo um padrão para o atendimento dos pacientes, nas primeiras 6 e 24 horas do diagnóstico. Foi introduzido a Terapia Precoce Guiada por Metas, que é uma estratégia de ressuscitação mais definitiva para manter o equilíbrio entre a oferta e a demanda de oxigênio. O primeiro suporte é reposição volêmica, indicada em pacientes com sepse grave e lactato sérico $4 \mathrm{mmol} / \mathrm{l}$ ou hipotensão refratária. As seguintes metas devem ser alcançadas em 6 horas: pressão venosa central $8-12 \mathrm{mmHg}$, pressão arterial média $65 \mathrm{mmHg}$, débito urinário 0,5 $\mathrm{ml} / \mathrm{kg} /$ hora e saturação venosa central de oxigênio $70 \%$. Todo fluido administrado deve ser computado na reposição hídrica em 24 horas. Reposição volêmica agressiva nas primeiras horas tem impacto expressivo na mortalidade. Conclusão: A sepse é uma doença de alta morbimortalidade, que demanda um atendimento de excelência nas unidades de emergência e terapia intensiva. Visando diminuir essa incidência é necessária medidas e preparo aos profissionais de saúde acerca da gravidade da doença e detecção precoce dos sinais primários, o que é crucial para um melhor prognóstico.

Descritores: Reposição Volêmica. Sepse. Tratamento. 


\section{AFECÇÕES DERMATOLógicas RELACIONADAS À COVID-19: UMA REVISÃo DE LITERATURA}

Fernando Henrique Artuzo Mathiel, Igor Jun Shigaki Okamoto, Juliana Caroline Mendonça Justino, Letícia Lopes Soares, Márcio Cesar Reino Gaggini (orientador)

Categoria: Painel

Introdução: Várias foram as manifestações cutâneas descritas relacionadas à COVID-19 antes, durante ou depois do surgimento de outros sintomas da doença, como exantemas, erupções urticariformes e lesões vesiculares. Objetivo: Revisar, através da literatura, as principais manifestações cutâneas descritas relacionadas à infecção pelo SARS-CoV-2. Metodologia: Revisão narrativa da literatura pela plataforma PubMed, cruzando os termos "Covid-19 and skin". Foram analisados artigos publicados entre abril de 2020 e abril de 2021, todos escritos em língua inglesa. Foram excluídos artigos que não continham informações sobre as alterações cutâneas relacionadas à infecção pelo SARS-CoV-2. Resultados: O eritema pérnio mostrou ser a manifestação dermatológica mais comum. Em uma parcela significativa dos casos, foi o único sinal encontrado da doença. Com duração média de 14 dias. Erupções vesiculares: surgem no início dos sintomas sistêmicos, até o terceiro dia, com duração média de 8 dias. Não houve associação com a gravidade da doença. Lesões urticárias: mais comumente distribuídas em tronco ou dispersas pelo corpo. Houve associação com casos graves da doença. $O$ aparecimento das lesões foi concomitante a outros sintomas, com duração de 6 a 8 dias. Diferentes padrões de exantemas e enantemas: surgiram simultaneamente a outros sintomas gerais da doença. Relacionados a um pior prognóstico. Com duração média de 6 a 8 dias. Um importante diagnóstico diferencial, no Brasil, é a dengue. Livedo: observado em um menor número de pacientes. Pode ser consequente à vasculopatia trombótica causada pelo vírus, com possível evolução para necrose cutânea. Sua identificação é importante para definir o prognóstico. Isquemia cutânea e necrose: descritas em menor número de casos e relacionadas à maior gravidade da doença. Podem ser indicativos de Coagulopatia Intravascular Disseminada. Os achados descritos acima estão em ordem decrescente de prevalência. Conclusão: Todas as lesões cutâneas apresentadas são inespecíficas, não sendo possível obter uma confirmação diagnóstica apenas com estes achados. A relação entre as manifestações dermatológicas e a infecção pela COVID-19 foi determinada pelo vínculo temporal entre ambos. Entendê-la ajudaria na compreensão da clínica do paciente e a relação das manifestações com seu tratamento e prognóstico.

Descritores: Coronavírus. Dermatopatias. Manifestações Cutâneas. 


\section{ALTERAÇÕES APRESENTADAS NA SAÚDE MENTAL E COMPORTAMENTAL MEDIANTE A PANDEMIA DE COVID-19}

Ana Paula Romualdo Fernandes, Anna Raquel Marques Gomes, Letícia Martins Bertati, Natália Cristina de Aveiro, Leda Ferraz (Orientadora)

Categoria: Painel

Introdução: De acordo com a Organização Mundial da Saúde, foi recomendado medidas para conter a transmissibilidade do Sars-CoV-2, incluindo: distanciamento social, como forma de prevenção à doença; isolamento social, para os indivíduos infectados, e quarentena, em caso de potencial exposição. Tais medidas restritivas atingem a humanidade de forma negativa, que têm a necessidade de viver em coletivo, podendo produzir sofrimento psíquico e desencadeando sintomas como estresse e transtorno de ansiedade. Portanto, é importante se estabelecer os efeitos psicológicos, alterações na saúde mental, efeitos no humor e estilo de vida relacionados à esta enfermidade. Objetivo: determinar as alterações apresentadas na saúde mental e comportamental humana mediante a pandemia de covid-19. Material e Método: Trata-se de uma pesquisa bibliográfica, do tipo revisão de literatura. Inicialmente os artigos foram retirados das bases de dados Google Acadêmico, Pubmed e Scielo, através do uso dos descritores "distanciamento social", "isolamento social" e "saúde mental". Os critérios de inclusão foram: artigos publicados em português e inglês disponíveis na íntegra, entre 2020 e 2021. Os trabalhos que não abordassem conceitos relevantes para o alcance do objetivo e não estivessem de acordo com os critérios de elegibilidade, foram excluídos. Resultado: Após análise da literatura, verificou-se que os sintomas de solidão, tristeza, ansiedade, distúrbios do sono e até mesmo depressão estavam presentes no cotidiano dos indivíduos estudados, mostrando também que além da alimentação menos saudável e da redução da atividade física, cerca de $20 \%$ dos participantes aumentaram o consumo de bebida alcoólica e tabaco como mecanismo de escape. Outro dado importante é que esses sentimentos são predominantes no sexo feminino na idade entre 18 e 29 anos, estudantes e com antecedentes de depressão, e são agravados pelo uso de medicação para dormir. Conclusão: Em suma, desde o início da pandemia observou-se diversos sintomas que afetaram a saúde mental e comportamental humana, sendo capaz de repercutir na qualidade de vida, aumentando os sentimentos de tristeza, depressão e ansiedade. Para melhor entendimento de todo esse processo, ainda se necessita de mais pesquisas para o melhor manejo no tratamento dessas desordens mentais, emocionais e comportamentais.

Descritores: Distanciamento Social. Isolamento Social. Saúde mental. 


\section{ALTERAÇÕES NA SAÚdE MENTAL DURANTE A PANDEMIA DE COVID-19 E 0 DESENVOLVIMENTO DA ALIMENTAÇÃO EMOCIONAL}

Emanoel de Oliveira Araújo, Júlia Medina Presente, Larissa Leslye Ribeiro, Tathiane Francisco Alves, Leda Ferraz (orientadora)

Categoria: Painel

Introdução: Desde março de 2020, a população foi impactada com a pandemia da COVID-19. Para amenizar o índice de contaminação, houve a implementação de medidas como ordens restritivas de circulação, quarentena e autoisolamento, produzindo grande efeito na saúde mental e aumentando casos de estresse, ansiedade e mudanças no estilo de vida. A ansiedade, neste contexto, possui correlação com comportamentos alimentares compulsivos e inadequados, denominada "Alimentação Emocional". Posto isso, mostra-se pertinente a investigação do impacto da COVID-19 nos padrões alimentares, com o propósito de direcionar futuras intervenções adequadas. Objetivo: Estabelecer a relação entre aumento do estresse e ansiedade em indivíduos expostos a ambientes estressores durante a pandemia, com a presença da alimentação emocional. Material e Método: Trata-se de uma pesquisa bibliográfica, do tipo revisão de literatura. Inicialmente os artigos foram retirados das bases de dados do Pubmed, Google Acadêmico e Biblioteca Virtual em Saúde, utilizando os descritores "COVID-19", "ansiedade", "comportamento alimentar". Os critérios de inclusão foram: artigos que abordassem a temática central, em inglês, português ou espanhol, disponíveis na íntegra e publicados entre 2019 e 2021. Os trabalhos que não abordassem conceitos relevantes para o alcance do objetivo e não estivessem de acordo com os critérios de elegibilidade, foram excluídos. Resultado: Observou-se uma sequência de associações relacionadas à saúde mental: a relação de ambientes estressores com comportamentos psíquicos incomuns e, muitas vezes, patológicos. Consonantemente, a maioria dos estudos descrevem a desordem do comportamento alimentar como um desarranjo impulsivo para bem-estar momentâneo, com hábito autorreferido de aumento da ingestão de alimentos com alta densidade energética, que promove um aumento do Índice de Massa Corporal, associado aos pacientes suscetíveis a alimentação emocional durante a pandemia. Quanto às alterações de peso corporal, sob uma análise geral, não foi possível observar grandes variações estatísticas entre os grupos estudados. Conclusão: Em resumo, a pandemia da COVID-19 criou um ambiente estressante e de medo, proporcionando a tendência de alimentação emocional como resposta a ansiedade, o que torna necessário a elaboração de diretrizes de saúde focando nas práticas alimentares saudáveis para este público-alvo.

Descritores: COVID-19. Ansiedade. Comportamento Alimentar. 


\section{ARTRITE REUMATOIDE E CÂNCER DE MAMA: UMA REVISÃO SISTEMÁTICA}

Janayne Fernandes da Silva, Jane Silvia Cardoso, Lernardo Cassimiro Leite, Renan Furquim Prieto, Taísa Morete da Silva (orientadora)

Categoria: Painel

Introdução: A artrite reumatoide (AR) é uma doença inflamatória crônica autoimune, que acomete as articulações, outros órgãos e sistemas. Atinge principalmente mulheres, com início em torno dos 30 aos 40 anos de idade. O câncer de mama (CM) é uma doença causada pela multiplicação desordenada de células anormais na mama e com capacidade de invadir outros órgãos e tecidos. É mais comum nas mulheres, acometendo $1 \mathrm{em}$ cada 10 ao longo da vida. A AR decorre de ativação inadequada do sistema imunológico, causando inflamação crônica, podendo aumentar o risco de carcinogênese. As neoplasias também podem aumentar o risco de doenças autoimunes. Objetivo: avaliar o risco de câncer de mama em pacientes com artrite reumatoide comparando à população em geral. Material e Método: Foi realizado uma pesquisa bibliográfica nas bases de dados PubMed, SciELO e Google Acadêmico. Como palavra-chave utilizou-se os termos: artrite, artrite reumatoide e câncer de mama, de acordo com os Descritores em Ciências da Saúde (DeCS). A busca inicial resultou em 78 artigos; destes, 20 artigos preencheram os critérios de inclusão. Abordado como critério de inclusão artigos em inglês, português ou espanhol, em um período de 5 anos e que estivessem disponíveis na íntegra e acesso online grátis, e excluídos os estudos repetidos que não abordaram o objetivo da pesquisa. Resultados: As doenças autoimunes e neoplasias compartilham a patogênese influenciada por uma desregulação imunológica mediada por citocinas e quimiocinas, com capacidade de desencadearem uma inflamação crônica, resultando em lesão de órgãos e em déficit na resposta às infecções. O câncer de mama e as doenças autoimunes são patologias comumente encontradas em pessoas do sexo feminino. Nos artigos analisados observamos a incidência de tumores em pacientes com AR, porém não foram consensuais em todos os 20 artigos estudados. Conclusão: Durante a realização do estudo foi observado escassez de artigos que abordam o tema. Nos trabalhos encontrados, não há risco significativamente aumentado de câncer de mama em pacientes com AR, no entanto, a redução desses riscos ainda não é bem explicada. Sendo assim, é necessário cautela e mais estudos para confirmar os resultados no futuro.

Descritores: Artrite. Artrite Reumatoide. Câncer de Mama. 


\author{
AVALIAÇÃo dO CONHECIMENTO DOS MÉdICOS DA ATENÇÃo BÁSICA SOBRE \\ TRANSTORNO DO ESPECTRO AUTISTA \\ Isabela Harumi Gomi, Thabata Soares Terra, Thaís Cardoso Menis, Patrícia Michelassi Carrinho \\ Aureliano (Orientadora) \\ Categoria: Painel
}

Introdução: O Transtorno do Espectro Austista (TEA) caracteriza-se pelos déficits e dificuldades na comunicação e interação social, associados a interesses e atividades restritas e circunscritas. A etiopatogenia exata ainda é desconhecida, mas o modelo multifatorial é a hipótese mais aceita e se baseia em fatores ambientais, genéticos e imunológicos. O diagnóstico e o tratamento precoce do TEA possibilita maior desenvolvimento das capacidades do paciente. No SUS, considerando o princípio da integralidade é assegurado ao indivíduo diagnosticado com TEA o atendimento a todas as suas necessidades. Portanto, faz-se necessário o estímulo ao estudo sobre o TEA, a fim de garantir na Atenção Básica um diagnóstico precoce e um tratamento adequado. Objetivo: Avaliar o grau de conhecimento sobre o TEA nos médicos da Atenção Básica na cidade de Fernandópolis/SP. Material e Método: $O$ estudo foi realizado em 10 Unidades Básicas de Saúde do município de Fernandópolis/SP. Participaram do estudo 7 médicos da Rede de Atenção Básica do município de Fernandópolis/SP. Foi aplicado um questionário com 20 questões fechadas. Após a coleta de dados, esses foram tabulados em dados do Excel e colocado em planilhas estatísticas. Resultado: Houve dificuldade em aplicar o questionário, dos 20 questionários entregues, apenas 7 foram respondidos. Algumas questões tiveram $100 \%$ de acertos e outras 30\%, foi possível analisar que existe um conhecimento já estabelecido pelos profissionais, porém ainda existem dúvidas sobre o assunto. Conclusão: A maioria dos médicos tem um conhecimento básico sobre o TEA, mas através do questionário foi possível perceber que esse conhecimento precisa ser mais aprofundado, através de uma melhor instrução durante a formação acadêmica e uma percepção dos médicos já formados sobre a importância do estudo desse transtorno. Em suma, a Atenção Primária precisa valorizar o estudo sobre o TEA, pois é crescente o número de pessoas nessa condição que merecem atenção médica e que podem ter uma melhora significativa na qualidade de vida.

Descritores: Transtorno do Espectro Autista. Atenção Primária à Saúde. Educação Médica 


\section{AVALIAÇÃO IN VITRO DA ATIVIDADE ANTIFUNGICA DE ÓLEOS IN NATURA E OZONIZADOS}

Isadora Medrado Goulart, Matheus Alves de Souza, Miguel Pereira Goulart Neto, Dora Inés KozusnyAndrean (orientadora)

Categoria: Painel

Introdução: $O$ tratamento das micoses é realizado com antifúngicos, que, em alguns casos podem causar efeitos adversos. $O$ espectro de atividade dos antifúngicos é variável, podendo levar a falha no tratamento. Atualmente, há estudos que visam novos métodos de tratamentos, tais como uso de plantas medicinais e de ozônio. Objetivo: A pesquisa tem como objetivo avaliar a eficácia antifúngica dos óleos vegetais in natura e ozonizados. Metodologia: Para avaliar a atividade antimicrobiana de óleos vegetais in natura e ozonizados, foram utilizadas as seguintes cepas padrão: Trichophyton rubrum ATCC 28188 e Sporothrix ATCC 16345 (American Type Culture Collection). De acordo com a pesquisa realizada foram empregada foram empregados 6 tipos de óleos como tratamento antifúngico, sendo o óleo de melaleuca, o óleo de melaleuca ozonizado, o óleo de copaíba, óleo de copaíba ozonizado, óleo de coco e óleo de coco ozonizado. Resultados: Estes óleos são considerados metabólitos secundários extraídos de plantas, podendo ser utilizados como princípios ativos em produtos destinados ao tratamento de humanos devido a sua capacidade farmacológica. Os antifúngicos orais e tópicos são considerados tratamentos de longo prazo. Este fato remete alguns dilemas que diminuem a eficácia da propedêutica. Desse modo, pode-se listar: o custo, as reações adversas de medicamentos orais e a dificuldade de penetração de fármacos tópicos acabam levando ao abandono do tratamento. Assim, a utilização de óleos medicinais em aspecto normal e ozonizados como alternativa terapêutica vem sendo estudada uma vez que elas possuem uma abundância de moléculas bioativas, as quais são utilizadas no tratamento de doenças, promovendo resultados satisfatórios e bem estar aos portadores da comorbidade. Conclusão: Houve efeito significado do tempo, portanto o comportamento relacionado à sobrevivência dos microrganismos avaliados é influenciado pelo tempo de ação/efeito do bactericida, independente da dose avaliada. Para o teste de sobrevivência de Trichophyton rubrum nas doses com a presença dos óleos de coco, melaleuca e copaíba ozonizados, o tempo de ação/efeito do bactericida é mais eficiente, ou seja, a redução da população dos microrganismos ocorre em tempo menor. Nesse mesmo contexto, associado ao menor tempo para ação do bactericida, no teste de sobrevivência de Sporothrix schenckii o óleo de Melaleuca se destacou, independentemente de ser ou não utilizado na forma ozonizada.

Descritores: Trichophyton rubrum. Trichophyton mentagrophytes. Sporothrix schenckii. 


\section{BIOSSEGURANÇA DO SETOR DE RADIODIAGNÓSTICO}

Étore Scapin Baroni, Janayne Fernandes da Silva, Miguel Pereira Goulart Neto, Nathália Regina Gasparelli Herrero Zinezi Rodrigues, Otávio Mendes Amêndola, Henrique César Scapin Ximenes (orientador)

Categoria: Painel

Introdução: A exposição da radiação aos profissionais de saúde ocorre principalmente nos procedimentos de diagnóstico por imagem devido à alta taxa de radiação. As radiações ionizantes causam efeitos biológicos que podem alterar a cadeia de DNA por mutações genéticas, sendo mais comum em órgãos com alta síntese celular como epitélio, osso, mamas, tireoide, gônodas e feto. Objetivo: $O$ trabalho tem como objetivo revisar a literatura cientifica em relação à biossegurança do setor de radiodiagnóstico. Material e Método: A metodologia empregada é de caráter analítico por meio de uma revisão de literatura bibliográfica. Os dados extraídos na pesquisa foram a partir do PubMed com os descritores: "Containment of Biohazards" e "Diagnostic Imaging" de acordo com os Descritores em Ciências da Saúde (DeCS). Para efetuar o cruzamento destes foi utilizado o operador booleano AND, encontrados 31 artigos e após critérios de inclusão e exclusão, 11 artigos foram utilizados. Os utilizados para a inclusão: artigos em inglês, português ou espanhol, entre junho de 2015 a julho de 2021, e disponíveis na íntegra e para acesso online grátis. Excluíram-se, os estudos que não abordassem o conceito relevante para o alcance do objetivo; estudos repetidos; segundo critérios de qualidade metodológica. Resultado: $O$ descumprimento das normas de biossegurança ainda é comum dentro de unidades de saúde. Diante desse fato, os Equipamentos de Proteção Individual (EPIs) são barreiras físicas, cujo objetivo é garantir a proteção do profissional na área de saúde, especificamente da radiologia. É importante a utilização de alguns equipamentos de proteção radiológica, tais como avental ou capote, protetores de tireoide, luvas, óculos, além de avaliações periódicas de dosímetro (monitor que mede uma grandeza radiológica) para monitorar as doses recebidas pelos profissionais durante o trabalho. De acordo com a Norma Regulamentadora 32 (NR32) e do Ministério da Saúde que estabelecem as diretrizes básicas de proteção radiológica, todos os procedimentos realizados devem estar dentro dos padrões técnicos de qualidade obedecendo às normas de biossegurança. Conclusão: A problemática de biossegurança é algo global e constante, sendo necessário a atenção e um olhar com cuidado dos gestores de instituições de saúde e a implantação de educação continuada na intenção de diminuir riscos inerentes à saúde dos colaboradores e melhorando a segurança do paciente assistido.

Descritores: Biossegurança. Diagnóstico por Imagem. 


\section{CARACTERIZAÇÃO DA COAGULAÇÃO INTRAVASCULAR DISSEMINADA NO TRAUMA}

Bruno Rezende Santana de Andrade, Larissa Leslye Ribeiro, Samuel José Nunes, Vinnícius Moreira do Prado Ferreira, Joseana Gomes Salustiano (orientadora)

Categoria: Painel

Introdução: Dentre as causas de morte evitáveis, o trauma é a maior, constituindo um grave problema de saúde pública. Na ocorrência de um trauma grave há uma lesão na parede do vaso sanguíneo, expondo o colágeno subendotelial, propiciando adesão plaquetária e interação entre os componentes celulares e humorais do sistema hemostático. A atividade pró-coagulante é controlada por cascatas anticoagulantes contrarreguladoras, mas em traumas graves as atividades de ambos estão desreguladas. Objetivo: correlacionar a coagulação disseminada intravascular e a coagulopatia induzida pelo trauma, respaldado em dados científicos. Metodologia: As bases de dados usadas foram PubMed e Biblioteca Virtual da Saúde. As pesquisas usaram termos como: Coagulopatia, Coagulação intravascular disseminada, Coagulopatia induzida pelo trauma e Trauma. Foram usados artigos dos últimos 5 anos na língua inglesa e portuguesa disponíveis na íntegra. Resultados: A coagulopatia induzida pelo trauma (CIT) é o déficit da produção de uma hemostasia adequada após ação traumática. Por décadas acreditou-se que a CIT era uma coagulação intravascular disseminada (CIVD) com caráter fibrinolítico, porém, a CIVD é a patogênese inicial e predominante da coagulopatia na fase aguda do trauma. A CIVD se caracteriza pela ativação intravascular da coagulação sem local específico, gerando dano à microvasculatura e disfunção orgânica. Ela é dividida em fenótipos: fibrinolítico (hemorrágico) e antifibrinolítico (trombótico). O fibrinolítico é associado à fase inicial do trauma que gera uma hiperfibrinólise e hiperfibrinogenólise contribuindo para hemorragia maciça. $\mathrm{Na}$ fase tardia do trauma, o fenótipo trombótico predomina originando possível falência de múltiplos órgãos. A hiperfibrinólise, hiperfibrinogenólise e a ativação da coagulação são simultâneas, com isso plaquetas e fatores de coagulação serão consumidos, levando a pior desfecho clínico. Conclusão: Mediante a análise inferimos que há íntima correlação entre a CIVD e a CIT. A CIVD é a patogênese inicial na fase aguda do trauma, e se mostra como um fator fundamental para a caracterização da CIT.

Descritores: Coagulação Intravascular Disseminada. Coagulação Sanguínea. Trauma. 


\section{CIGARROS ELETRÔNICOS E EVALI}

Everhton Paulo de Freitas Primo, Giovana Maschietto Sussai, Letícia Okazaki Reis, Luana Martins Camilo, Raissa Silva Frota (orientadora)

Categoria: Painel

Introdução: Os cigarros eletrônicos estão se tornando cada vez mais populares devido a portabilidade, menos odores característicos e por serem comercializados como uma alternativa mais segura aos cigarros tradicionais. Entretanto, as substâncias associadas a vaporização podem liberar subprodutos que desencadeiam processos inflamatórios pulmonares propiciando o surgimento da injúria pulmonar aguda (EVALI). Objetivo: Com base no exposto, este trabalho visou realizar uma revisão de literatura de estudos acerca do uso de cigarros eletrônicos e sua relação com o desenvolvimento da insuficiência pulmonar aguda. Metodologia: Trata-se de uma revisão de literatura realizada com estudos indexados na plataforma de dados da PubMed, na qual obteve-se 11 resultados. Utilizou-se como delineamento de inclusão artigos científicos de revisão de literatura e revisão sistemática, publicados na língua inglesa, na íntegra, disponibilizados on-line, gratuitos, tratando sobre humanos, publicados nos últimos 5 anos com os descritores: "Vaping" e "EVALI". Resultado: Em dois dos estudos analisados foi possível compreender o funcionamento dos cigarros eletrônicos, os quais convertem líquido em aerossol através da adição de calor. A base líquida é composta por solventes, aromatizantes e nicotina, podendo conter outras substâncias. A ação de vaporizar leva a degradação dos componentes dos e-cigarros, resultando na liberação de compostos perigosos a saúde humana, como o acetato de vitamina E, agente espessante do THC. Segundo Winnicka et al., tais substâncias levam a reações inflamatórias que comprometem a barreira alveolarcapilar, a produção de surfactante e causam efeitos na árvore brônquica associados ao comprometimento mucociliar. Sintomas como dispneia, tosse não produtiva, dor torácica e hemoptise usualmente estão presentes. O estudo de Layden et al., sugere que existem 4 padrões radiográficos EVALI discretos, como pneumonia eosinofílica aguda, dano alveolar difuso, pneumonia em organização e pneumonia lipoide. Conclusão: $O$ tabagismo é considerado a causa de doença mais evitável em todo o mundo e, os e-cigarros, provavelmente irão contribuir para uma maior redução no número de fumantes de cigarros tradicionais. No entanto, atualmente, há evidências substanciais de que os e-cigarros podem causar doenças pulmonares, incluindo a EVALI. A ressalva é que ainda faltam pesquisas abrangentes e definitivas acerca do tema e seu uso deve continuar sendo advertido pelos médicos.

Descritores: Vaping, EVALI 


\section{CIRURGIA METABÓLICA PARA TRATAMENTO DO DIABETES MELLITUS TIPO 2 REVISÃO DA LITERATURA}

Eloisa Carvalho Duzzi, Frank Bueno Junqueira, Karen Sabrina Moreira Benedito, Luciano de Siqueira Bracci Junior, Renato Tomaz da Silva

Categoria: Painel

Introdução: O diabetes mellitus tipo 2 (DM2) é uma das maiores causas de morte devido à sua relação direta com as doenças cardiovasculares, cerebrovasculares e renais. Pacientes portadores de DM2 apresentam resistência à ação da insulina associada à incapacidade de sua secreção. Dentre os fatores de risco para o DM2 destaca-se o excesso de peso. Enquanto novas drogas continuam a melhorar o tratamento clínico, a maioria dos pacientes nunca atingem os objetivos definidos para o sucesso da terapêutica, o que abre espaço para novas possibilidades de tratamento como a cirurgia. Objetivos: Descrever os resultados de pacientes portadores de DM2 e obesidade submetidos a cirurgias metabólicas. Metodologia: Foram utilizadas as bases para coleta de dados, usuais em revisões sistemáticas: PubMed, Scielo e LILACS com os descritivos: cirurgia metabólica, cirurgia gastrointestinal, obesidade, diabetes mellitus tipo 2. Resultados: A relação entre as alterações metabólicas dos pacientes e a perda de peso sugere interação entre a quantidade de tecido adiposo e o nível glicêmico, tendo os fatores endócrinos como principais reguladores desse sistema. Diversos mecanismos contribuem para o controle do diabetes no pós-operatório da cirurgia bariátrica sendo a explicação mais plausível é que a perda de peso promove diminuição da resistência periférica à insulina. Foi demonstrado que o bypass gástrico ampliam os níveis de adiponectina, que aumenta a sensibilidade à insulina e a concentração de receptores para a insulina no músculo, reduz a quantidade de lipídios intramusculares e moléculas de acetil co-enzima $A$, ambos indicativos de redução da resistência periférica à insulina. $O$ transporte de glicose para as fibras musculares é aumentado e a disponibilidade de glicose corporal melhora de $27 \%$ para $78 \%$ dos níveis observados em um grupo controle com peso normal. Conclusões: Os procedimentos cirúrgicos sobre o trato gastrointestinal, principalmente as cirurgias bariátricas, proporcionam controle metabólico do DM2 explicado pela perda de peso e diminuição da ingestão de alimentos. Entre os procedimentos com os melhores resultados estão as derivações biliopancreáticas (98\%) seguidas pelo bypass gástrico (84\%) e pela banda gástrica (48\%). Nas derivações biliopancreáticas e no bypass gástrico ocorre ainda alteração na secreção de hormônios, principalmente os de origem no trato digestivo.

Descritores: cirurgia metabólica, obesidade, diabetes mellitus tipo 2 


\section{CIRURGIA MINIMAMENTE INVASIVA DO CÂNCER GÁSTRICO: UMA REVISÃO DE LITERATURA} Amanda Oliva Spaziani, Amanda Pinato Alves da Costa, Ana Paula dos Santos Zuliani, Letícia Passolongo Silva, Livia Lohaine Alencar Antunes, Rafaela Vellozo Martins

Categoria: Painel

Introdução: O câncer gástrico no Brasil é o terceiro tumor maligno mais frequente entre os homens e o quinto entre as mulheres. Dentre os principais fatores de risco são observados fatores ambientais, nutricionais, sociais, médicos e genéticos. A cirurgia minimamente invasiva abrange toda a cavidade interna do corpo humano por uma incisão que tem seu tamanho definido pelo médico cirurgião que vai manipular os instrumentos cirúrgicos, de acordo com a finalidade cirúrgica. Objetivo: revisar na literatura o tratamento do câncer gástrico por meio da cirurgia minimamente invasiva. Metodologia: Trata-se de uma revisão bibliográfica da literatura de cunho exploratório. As publicações selecionadas foram publicadas no período compreendido entre 1997 e 2021 junto às bases de dados eletrônicas, Biblioteca Virtual de Saúde (BVS) e Literatura Latino-Americana e do Caribe em Ciências da Saúde (LILACS). Resultados: Os descritos utilizados foram câncer gástrico e laparoscopia em português ou inglês. O tratamento cirúrgico para a cura do câncer gástrico é expressamente o mais indicado, e a extensão da ressecção deste câncer depende da sua localização e tamanho identificados no préoperatório pelo estadiamento. Para este procedimento, o padrão é a gastrectomia aberta, porém as cirurgias minimamente invasivas vêm tomando lugar nas ressecções. Para carcinomas gástricos distais, que envolvem o corpo e o antro do estômago, realiza uma gastrectomia distal enquanto que nas lesões proximais envolvendo o fundo do estômago, faz uma gastrectomia proximal. A execução de ressecção endoscópica pode ser realizada em câncer gástrico inicial ou com acometimento limitado da parede gástrica sem metástase linfonodal, por isso ela deve ser usada afim de evitar uma gastrectomia apesar de ter a desvantagem de não poder realizar a ressecção. Em casos de câncer gástrico avançado, ainda não possível afirmar a eficácia no tratamento. Isso porque quando o indivíduo chega neste estágio de doença, acompanha também o acometimento de outros órgãos. Conclusão: Quando tratamos de câncer gástrico precoce, a cirurgia minimamente invasiva já é considerada o procedimento mais seguro e eficaz. Porém, ainda existem fatores a serem aprimorados para sua exclusividade no tratamento, alguns dos fatores são alto custo para a saúde pública, dificuldade de ensino do método e a descentralização em tratamentos oncológicos.

Descritores: Câncer gástrico, laparoscopia, cirurgia minimamente invasiva. 


\section{COVID-19 E SÍNDROME DE BURNOUT: INCIDÊNCIA DOS CASOS}

Eulália Assis Marques, Isabella Corrêa de Miranda, Manoan Simioni Ferreira, Márcio Miranda Santos, Thaísa Bergamini Ferreira Souza, Marli dos Santos Rosa Moretti (orientadora)

Categoria: Painel

Introdução: O rápido avanço do COVID-19 no mundo instalou a pandemia causada pelo vírus SARSCoV-2 de forma abrupta e inesperada. Com isso, nota-se o aumento de danos psicológicos e físicos em todo segmento social, em especial aos atuantes na área da saúde, devido a ampliação de rotinas que já eram exaustivas, risco de contaminação, alta pressão no ambiente hospitalar diante desse vírus, carência de EPIs e a falta de alguns medicamentos. Dessa forma, estudos revelaram que ocorreu o aumento da probabilidade de desenvolver depressão, ansiedade e transtorno de estresse pós-traumático, fatores esses que elevam o risco da Síndrome de Burnout, um distúrbio emocional devido ao esgotamento por consequência de estresse advindos do trabalho excessivo. Objetivo: tem como ideia principal esclarecer o impacto da pandemia de COVID-19 e Síndrome de Burnout nos profissionais da saúde. Metodologia: Trata-se de uma revisão literária em que se utilizou os bancos de dados Scientific Electronic Library Online (SciELO), Google Acadêmico e PubMed para obtenção de dados. Como estratégia de busca desta revisão, foi utilizado os seguintes descritores em português: Esgotamento profissional, COVID-19; em inglês: Burnout Psychological e COVID-19. Ao todo, foram utilizados nove estudos para a realização da revisão literária. Resultados: obteve-se importantes resultados acerca do aumento de casos de Síndrome de Burnout durante a pandemia do COVID-19 em profissionais da saúde. De acordo com os estudos realizados, em 2021 houve aumento de $31,8 \%$ na depressão em parteiras e enfermeiras durante a pandemia de doença coronavírus 2019. Ademais, profissionais responsáveis pelo atendimento de crianças, tiveram maiores chances de desenvolver exaustão emocional; além de enfermeiros do sexo masculino serem os mais afetados emocionalmente, segundo o estudo. Conclusão: Em suma, a falta de flexibilização de horário; trabalho em turnos irregulares; disponibilização inadequada dos instrumentos de trabalho; ambiente de trabalho precário durante a pandemia causada pelo vírus SARS-CoV-2 são fatores que contribuíram para um aumento de problemas psicológicos, tais como a depressão e exaustão emocional e, consequentemente, aumento da síndrome de Burnout.

Descritores: Esgotamento profissional, Burnout Psychological, COVID-19 


\section{DETECÇÃO DA ENDOMETRIOSE NA RESSONÂNCIA MAGNÉTICA}

José Miguel de Souza Maia, Jozyane Ribeiro Fuginami Gotto, Juliana da Cruz Nunes Silva, Mariana Caroline Carocia, Miguel Pereira Goulart Neto, Lucas Coimbra da Cruz (orientador)

Categoria: Painel

Introdução: A endometriose é caracterizada pela presença de tecido endometrial ectópico que acomete mulheres em idade reprodutiva e está relacionada à dor pélvica e infertilidade. Não há uma patogênese bem definida, possui um diagnóstico clínico difícil, constituído por história, exame físico, ressonância magnética (RM), laparoscopia e biópsia de lesões suspeitas. Objetivo: revisar a literatura científica em relação à detecção da endometriose na ressonância magnética. Metodologia: A metodologia empregada é de caráter analítico por meio de uma revisão de literatura bibliográfica. Os dados extraídos na pesquisa foram a partir do US National Library of Medicine (PubMed) com os descritores: Endometriosis e Magnetic Resonance Imaging, de acordo com os Descritores em Ciências de Saúde (DeCS). Foram encontrados 1.200 artigos e, após critérios de inclusão e exclusão, 16 artigos foram utilizados. Os utilizados para inclusão: artigos em inglês e português de 2015 a 2021. Excluíram-se os estudos que não abordassem o conceito relevante para o alcance do objetivo. Resultado: Segundo Nathaly Andrade Gomes, no artigo: A ressonância magnética no diagnóstico de endometriose profunda com acometimento intestinal: relato de caso, a endometriose pode se desenvolver em qualquer região da pelve e superfícies peritoneais extras pélvicas, mas as áreas mais comuns são ovário, peritônio pélvico e septo retovaginal. De acordo com Antônio Carlos Coutinho Junior, no artigo: Ressonância magnética na endometriose pélvica profunda: ensaio iconográfico, embora possua algumas limitações, a RM é muito importante no diagnóstico da endometriose, pois permite a identificação de lesões de permeio a aderências e a avaliação da extensão das lesões subperitoneais. Ademais, os achados de imagem podem variar: pequenos implantes infiltrativos, limitada ou com focos de alto sinal com supressão de gordura e hemorragias; lesões sólidas profundas com focos hiperintensos e supressão de gordura devido a glândulas endometriais ectasionadas com conteúdo hemorrágico e tecido fibrótico; e endometriose visceral envolvendo as paredes vesical, localizada ou difusa, e retal, essa com baixa sensibilidade no diagnóstico pela RM. Conclusões: É imprescindível que a paciente com suspeita de endometriose realize a RM, visto que é um excelente exame para a detecção da doença, possibilitando um rápido tratamento para a mesma.

Descritores: Endometriose, Imagem de Ressonância Magnética 


\section{DIABETES MELLITUS TIPO 2 NA INFÂNCIA}

Luísa Masson Francisco, Marcela Monteiro Soares, Lilian Maria G. Soares (orientadora)

Categoria: Painel

Introdução: O Diabetes Mellitus tipo 2 é caracterizado pela resistência periférica à insulina e, em um estágio mais avançado, pela destruição das células beta pancreáticas produtoras desse hormônio. Essa doença era conhecida por acometer principalmente a idade adulta, porém, com a mudança do estilo de vida em todas as faixas etárias, ela vem sendo observada com o aumento da prevalência na infância. As crianças estão cada vez mais sedentárias e consumindo alimentos pobres em nutrientes e ricos em calorias e gorduras, propiciando a obesidade. Quanto mais açúcar o indivíduo consome, mais o pâncreas libera insulina, acelerando o desgaste das células que a produzem. Objetivos: Objetiva-se, por meio deste trabalho, identificar, na bibliografia selecionada, os motivos do aumento da prevalência de Diabetes Mellitus tipo 2 na infância, além de compreender a fisiopatologia da doença relacionada a essa idade. Metodologia: Trata-se de uma pesquisa bibliográfica, do tipo revisão de literatura, tendo como fonte artigos científicos referentes ao Diabetes Mellitus tipo 2 na infância. Os artigos foram retirados das bases de dados Google Acadêmico e Scielo; foram selecionados os trabalhos publicados de 2004 a 2021. Resultados: A obesidade infantil é considerada o maior fator de risco para o diabetes mellitus tipo 2. Essa doença, na maioria das vezes, apresenta-se assintomática nas crianças, retardando o diagnóstico. Apenas $30 \%$ delas terão poliúria, polidipsia, leve emagrecimento e acanthosis nigricans. Ainda, podem apresentar cetonúria e/ou cetoacidose, náusea, vômito e desidratação. Para esses casos, recomenda-se a insulinoterapia. $O$ diagnóstico do Diabetes tipo 2 na infância é feito a partir de critérios clínicos e da apresentação da glicosúria e/ou hiperglicemia em exames de rotina. As complicações do diabetes a longo prazo são doenças micro e macrovasculares, retinopatia, nefropatia e neuropatia diabética. $O$ tratamento varia de acordo com a apresentação clínica. Nas crianças assintomáticas, orienta-se quanto a alteração do estilo de vida e dos hábitos alimentares, enquanto, nas sintomáticas, utiliza-se a terapia farmacológica com metformina, sulfonilureias, glitinides e insulina. Conclusão: Desse modo, concluise que, devido ao estilo de vida que as pessoas estão adquirindo nos últimos anos, as crianças ficam cada vez mais expostas a esses fatores de risco desde muito cedo, desencadeando doenças que antes eram consideradas apenas da vida adulta.

Descritores: Diabetes Mellitus; Diabetes Mellitus tipo 2; Infância 


\section{DOENÇA HEPÁTICA ALCOÓLICA}

lara Desiree Vizotto, Juliana da Cruz Nunes Silva, Luiza Mahiara Calixto Zussa, Maryellen Orbolato Patussi, Paulo Giovani Padilha Dos Santos, Marli dos Santos Rosa Moretti (Orientador)

Categoria: Painel

Introdução: A doença hepática alcoólica (ALD), reporta-se aos danos que acometem o fígado e suas funções, devido ao excesso do consumo de álcool. Consiste em várias patologias: esteatose, hepatite alcoólica, esteatohepatite, hepatite crônica com fibrose hepática, cirrose e câncer de fígado. A patogênese por trás da doença hepática alcoólica (ALD) possui mecanismos complexos e complicados devido ao comprometimento imunológico. É a segunda causa mais comum de morte humana total a cada ano. Consumir bebida alcoólica a longo prazo em excesso, pode causar uma inflamação por meio de acúmulo de algumas substâncias que causam toxicidade no fígado, e estresse oxidativo através do metabolismo do álcool. Objetivo: trabalho tem como objetivo através da revisão de literatura, dar enfoque a doença hepática alcoólica, por ser uma doença prevalente e mortal, necessita de mais atenção em seus estudos, para uma melhora tanto no diagnóstico quanto no tratamento precoce. Material e Método: $O$ estudo realizado foi uma revisão narrativa da literatura. Os dados extraídos na pesquisa foram a partir do PubMed com os descritores: "Liver Cirrhosis, Alcoholic" e "Hepatitis, Alcoholic" de acordo com os Descritores em Ciências da Saúde (DeCS). Para efetuar o cruzamento destes foi utilizado o operador booleano AND, encontrados 849 artigos e após critérios de inclusão e exclusão, 8 artigos foram utilizados. Os utilizados para a inclusão: artigos em inglês, português ou espanhol, entre junho de 2016 a julho de 2021, e disponíveis na íntegra e para acesso online grátis. Resultado: A ALD como abordado acima, tem um amplo espectro de distúrbios, sendo uma das principais causas de morbidade e mortalidade no mundo. Na Europa a cirrose hepática alcoólica foi responsável por 493.300 mortes em 2010. Nos EUA, a mortalidade por ALD foi estimada em 5,5 por 100.000 em 2012. No mundo as mortes por AC ocupam cerca de $10 \%$ de todas as mortes atribuídas ao álcool. Conclusão: Diante da alta taxa de mortalidade, tendo um conhecimento razoável, sabendo-se do quanto se é complexo e complicado o conhecimento da sua fisiopatologia, epidemiologia, patogenicidade, é notável a falha na detecção precoce para que seja feito um bom diagnóstico clínico. Fica evidente também, a deficiência, das terapêuticas utilizadas para tratamento, sendo necessária a utilização de novas terapias e de uma atenção maior a essa doença que acomete muitos pacientes, e que tem um nível relativamente baixo nas pesquisas.

Descritores: cirrose hepática alcoólica, hepatite alcoólica 


\section{EFEITOS BIOLÓGICOS DA RADIAÇÃO IONIZANTE NA SAÚDE DO PACIENTE}

José Miguel de Souza Maia, Jozyane Ribeiro Fuginami Gotto, Juliana da Cruz Nunes Silva, Mariana Caroline Carocia, Miguel Pereira Goulart Neto, Lucas Coimbra Cruz (Orientador)

Categoria: Painel

Introdução: A energia da radiação pode ser transferida para o DNA, mudando sua estrutura, que é característica de efeitos diretos. Quando submetidas aos efeitos diretos da radiação (ionização), as moléculas de DNA ficam basicamente expostas a dois tipos de danos: mutações genéticas e quebras. Fontes de radiação ionizante são comuns na área de saúde (raios- $X$, tomografia computadorizada $e$ radioterapia) e produção de energia (usinas nucleares). A dose de radiação de uma pessoa pode ser aumentada de duas maneiras, contaminação e irradiação. A contaminação é o contato e retenção de materiais radioativos, geralmente pó ou líquido. A irradiação inclui a exposição à radiação, não a materiais radioativos, ou seja, nenhuma contaminação. Objetivos: Identificar os eventuais efeitos biológicos da radiação ionizante na saúde do paciente. Métodos: Para atingir os objetivos, decidiu-se realizar uma revisão sistemática. Os critérios de inclusão da pesquisa são: (i) o artigo ser original; (ii) o artigo ser qualitativo (iii) estarem disponíveis na íntegra de forma livre e isenta de custos. Em relação à estratégia de pesquisa, uma busca foi conduzida de 2017 a 2021 usando o banco de dados PubMed, recorrendo à seguinte sintaxe: ((lonizing radiation) AND (biological effects) AND (patient)). Resultados: Da busca realizada, foram encontrados 17 artigos, dos quais 12 foram excluídos por unanimidade pelos autores. Após os métodos e procedimentos explicitados, 05 artigos foram selecionados para revisão sistemática. Conclusão: $O$ risco de câncer desta exposição depende da dose, duração, idade da exposição e outros fatores, como a sensibilidade do tecido aos efeitos carcinogênicos da radiação. Quando uma pessoa é exposta à radiação por um curto período ou vários dias, a chamada síndrome aguda da radiação pode ocorrer. A dose sistêmica absorvida é de 0,25 a 1 Gray (Gy), o que pode causar náuseas, diarreia e depressão do sistema sanguíneo; se estiver entre 1 e 3 Gy, além dos sintomas anteriores, podem ter infecções causadas por patógenos oportunistas; aparecerá entre 3 e 5 Gy um sangramento, queda de cabelo e infertilidade temporária ou permanente; cerca de 10 Gy pode causar inflamação pulmonar e, para doses maiores, seus efeitos incluem danos ao sistema nervoso e cardiovascular, levando à morte em poucos dias.

Descritores: Energia da Radiação, Radiação lonizante, Efeitos Biológicos 


\section{ENDOCARDITE BACTERIANA POR COMPLICAÇÕES BUCAIS}

Isabella Manhoni Lima; Amanda Ferreira Garcia Queiroz; Gabriela Cristina da Silva Caldeira; Pollyane Laylla Ribeiro Dantas; Luciana Estevam Simonato (orientador)

Categoria: Painel

Introdução: A endocardite bacteriana é uma inflamação do endocárdio oriunda de uma bacteremia presença de bactérias na circulação sanguínea que acometem órgãos, como o coração, causando uma infecção local. Há pacientes com maiores riscos para contrair uma bacteremia, como história de doença cardíaca e de válvulas proteicas, além de episódio prévio de endocardite. Estudos mostram que procedimentos odontológicos são responsáveis pela maioria das bacteremias transitórias. As principais bactérias causadoras são Streptococcus e Staphylococcus, presentes na pele e nas mucosas. Devido à associação da endocardite ao tratamento odontológico foram feitos protocolos preventivos, sendo o primeiro publicado pela American Heart Association (AHA), consistindo na profilaxia com antibióticos. As recomendações da AHA dirigidas a pacientes que apresentam condições cardíacas de alto risco e necessitam de profilaxia antibiótica como em casos onde há histórico de endocardite, cardiopatia congênita cianótica não corrigida e usuário de prótese valvar. Objetivos: Ampliar o conhecimento dos profissionais de saúde em relação à endocardite bacteriana, além de evidenciar qual a melhor conduta a ser adotada para sua profilaxia e se há, de fato, necessidade da indicação de antibióticos. Material e Método: Pesquisa bibliográfica em forma de revisão de literatura utilizando busca em bases de dados eletrônicas: Scielo, PubMed, e Biblioteca Virtual em Saúde com as palavras chaves "Endocardite" e "Endocardite Bacteriana". Foram utilizados artigos no idioma português, completos, desde 2010. Foram excluídos os que não se referem a endocardite de forma central ou superficial. Resultados: A profilaxia de antibióticos é indicada para procedimentos odontológicos que sejam susceptíveis à endocardite bacteriana ou em pacientes que apresentem algum fator de risco. Conclusão: $O$ estudo demonstrou a importância da adesão à profilaxia antibiótica principalmente no grupo de pacientes com alto risco. É essencial priorizar a manutenção de uma boa saúde bucal e do biofilme dental, pois são fatores determinantes para ocorrência da endocardite. Assim, os profissionais de saúde devem se atentar à saúde bucal e suas complicações.

Descritores: Endocardite, Endocardite Bacteriana, Saúde Bucal. 


\section{FATORES RELACIONADOS AO GANHO DE PESO INTERDIALÍTICO NOS PACIENTES EM HEMODIÁLISE}

Amanda Spaziani, Giovana Maschietto Sussai, Isadora Medrado Goulart, Juliane Maschietto Sussai, Letícia Okazaki Reis, Raissa Frota

Categoria: Painel

Introdução: hemodiálise é um procedimento de filtragem do sangue para retirar toxinas e excesso de água no organismo, a técnica é indicada quando há perda significativa ou total das funções renais, como em casos de insuficiência renal aguda ou crônica. A adesão à ingestão adequada de líquidos é comumente mensurada por meio do ganho de peso interdialítico (GPID). Objetivos: Tem-se como objetivo elencar a importância do tema, visando realizar uma revisão sistemática acerca dos fatores relacionados ao ganho de peso interdialítico de pacientes em hemodiálise. Metodologia: Trata-se de uma revisão bibliográfica de caráter analítico realizada por meio de pesquisas nas bases de dados Scientific Electronic Library Online (SciELO) e na U. S. National Library of Medicine (PubMed) e Google Acadêmico por meio das palavras - chaves reposição hemodiálise, volume, insuficiência renal. Foram encontrados 750 artigos e após critérios de inclusão e exclusão, caso distanciasse do tema principal abordado, foram selecionados 20 artigos do período compreendido entre 2005 até 2021, disponíveis em PDF, de acesso on-line. Resultado: No presente trabalho, foi constatado que o \%GPID dos pacientes estudados foi influenciado pelo gênero, idade, tempo em tratamento hemodialítico. Os dados encontrados têm demonstrado que a presença de Diabetes Mellitus(DM) influencia no aumento do GPID, porém pacientes com DM apresentaram menor \%GPID. Acredita-se que estes pacientes talvez tenham o DM bem controlado, já que foi observado que o aumento do \%GPID está relacionado ao mau controle deste distúrbio. O percentual de pacientes com algum grau de desnutrição foi de 7,5\% de acordo com o IMC (Índice de Massa Corporal. e de 17\% conforme a ASG (Avaliação Subjetiva Global). Levando em consideração outros fatores além do peso atual, como a perda de peso, alimentação e exame físico. Conclusão: Pacientes sem função renal residual apresentaram maior acúmulo de potássio e ganho de peso ao longo do maior intervalo interdialítico. Mais estudos se fazem necessários no referido intervalo, com maior número de pacientes, visando confirmar esses dados e encontrar outras associações possivelmente não evidenciadas pelo pequeno tamanho da amostra estudada.

Descritores: Hemodiálise, Insuficiência Renal, Interdialítico 
FIBROMIALGIA E O SEU IMPACTO SOCIAL

Cassia Sousa Ferreira, Eleusa Gomes Muniz Ribeiro, Guilherme Henrique Pagliarani, Olívia Terra Pires, Polyanne Almeida Santos Chagas, Taísa Morete da Silva

Categoria: Painel

Introdução: A fibromialgia é uma síndrome dolorosa crônica, não inflamatória, que se manifesta no sistema musculoesquelético e pode apresentar diversas manifestações clínicas. Sua fisiopatologia envolve fatores genéticos e alterações endócrinas e autonômicas. É uma doença de relevância pública, pois, muitas vezes, culmina em incapacidade funcional. Objetivo desse estudo é analisar o impacto social da fibromialgia, ressaltando as complicações na qualidade de vida e a relevância das relações sociais para o enfrentamento da doença. Material e Método: Trata-se de uma revisão bibliográfica com abordagem qualitativa. Foram usados como critérios de inclusão: publicações científicas de 2017 a 2021, em português ou inglês, em forma de artigos ou livros. Foram utilizadas as seguintes bases de dados: Literatura Latino-Americana e do Caribe em Ciências da Saúde (LILACS), USA National Library of Medicine (MEDLINE/PubMed), biblioteca eletrônica Scientific Eletronic Library Online (SciELO), Scholar Google, Up to. Resultados: Evidenciou-se que as pessoas com fibromialgia que não recebem apoio social possuem mais sintomas depressivos e têm sua funcionalidade ainda mais prejudicada. Os pacientes sofrem estigma e invalidação por parte da sociedade, por se tratar de uma enfermidade que causa dor generalizada. Muitas vezes, a fibromialgia é subdiagnosticada, e o diagnóstico é feito incorretamente como transtorno depressivo. O melhor tratamento será aquele que é individualizado, envolvendo terapêutica multidisciplinar, que engloba atividade física, psicoterapia e tratamento farmacológico, que visam à redução dos sintomas. Ademais, o apoio familiar e social é necessário para o sucesso da terapêutica desta síndrome, por isso é de suma importância que o paciente não seja excluído e nem viva isolado, inserindo-se na família e na comunidade, criando um ambiente de compreensão, tanto do próprio doente, quanto das pessoas de sua convivência. Conclusão: A fibromialgia é uma doença crônica que não envolve apenas sintomas físicos, estando também associada a alterações emocionais. Assim, o tratamento multidisciplinar e o suporte social auxiliarão diretamente no enfrentamento da enfermidade, com melhora da qualidade de vida.

Descritores: Fibromialgia, Impacto Social, Qualidade de Vida Relacionada à Saúde. 


\section{HISTÓRIA DA CIRURGIA MINIMAMENTE INVASIVA: UMA REVISÃO DE LITERATURA}

Allana Caroline Viganó Bambila, Amanda Martins Pereira, Ana Paula dos Santos Zuliani, Gabriela do Santos Romero, Letícia Passolongo Slva, Amanda Olivia Spaziane (orientadora)

Categoria: Painel

Introdução: Originária do latim e do grego, respectivamente, as palavras scopium e skópion significam ver, observar. Associadas ao termo endo (porção interna) obtém-se endoscopia. Com o acesso à visualização da porção externa das vísceras ocas e também de órgãos parenquimatosos, na abordagem abdominal utiliza-se a palavra laparoscopia (por consagração, já que lapa, do grego, refere-se a flanco). Em nosso idioma, vídeo significa a parte do equipamento que permite a percepção visual da emissão de imagens. Objetivo: Considerando a importância do tema, esse trabalho visa relatar o disponível na literatura acerca da história da cirurgia minimamente invasiva. Metodologia: Essa pesquisa foi desenvolvida por meio de uma revisão de literatura nas bases de dados Scielo e PUBMED, foram selecionados artigos do período compreendido entre 2016 e 2021 a partir dos descritores: videolaparoscopia e cirurgia por vídeo. Foram excluídos da pesquisa os artigos incompletos e selecionados doze trabalhos para compor essa revisão. Resultados: $O$ crédito da realização da primeira laparoscopia cabe a Georg Kelling, que, em 1901, na Alemanha, submeteu um cão vivo ao procedimento, utilizando um cistoscópio. Entretanto, apenas em 1986, com o advento de câmeras filmadoras modernas (videochips), iniciou-se ampla difusão do método entre os cirurgiões gerais. Para eles, o marco inicial simbólico da cirurgia minimamente invasiva foi o ano de 1987, com a realização da primeira colecistectomia laparoscópica em Lyon, França, por Philippe Mouretl. Desde então, o crescimento da tecnologia de sua aplicabilidade vem ocorrendo de forma logarítmica. $O$ advento da cirurgia minimamente invasiva representou marco expressivo na evolução da cirurgia moderna. Foram efetuadas modificações em passos técnicos de resultados consagrados, visando permitir ou facilitar o novo tipo de abordagem. Uma nova opção terapêutica, ao se instalar, deve obrigatoriamente trazer melhores resultados para o paciente, ou pelo menos mantê-lo com reduzidos índices de morbidade e mortalidade, ou representar menor custo. Conclusão: Com o progresso tecnológico desse tipo de abordagem, outros órgãos, áreas anatômicas e cavidades também passaram a ser acessíveis, e, especialmente com melhor compreensão fisiopatológica, o termo genérico que melhor reflete o método é cirurgia minimamente invasiva.

Descritores: Videocâmera Endoscópica; Cirurgia Assistida por Computador; Cirurgia Guiada por Imagem; 


\section{IMPLANTAÇÃO DA TELERRADIOLOGIA EM CLÍNICAS E HOSPITAIS}

Étore Scapin Baroni, Henrique César Scapin Ximenes, Janayne Fernandes da Silva, Jozyane Ribeiro Fuginami Gotto, Nathália Regina Gasparelli Herrero Zinezi Rodrigues, Otávio Mendes Amêndola

Categoria: Painel

Introdução: A telerradiologia é um conjunto que envolve tecnologias de informação e meios de comunicação, através de equipamentos e softwares que possibilitam a transferência de imagens radiológicas de um local para o outro. No Brasil, inúmeras experiências acadêmicas e privadas têm sido desenvolvidas em telerradiologia, buscando facilitar o acesso a serviços radiológicos através da interpretação remota de imagens por especialistas da área da imagenologia, em regiões rurais ou em locais com escassez destes especialistas. Porém, é fundamental que estejamos atentos para questões até então inéditas, mas que necessariamente devem ser discutidas para que estabeleçamos as diretrizes técnicas, éticas e profissionais que permitam o uso seguro e proveitoso dessas novas ferramentas. Objetivo: Este trabalho tem como objetivo revisar a literatura cientifica em relação à Implantação da telerradiologia em clínicas e hospitais. Material e Método: A metodologia empregada é de caráter analítico por meio de uma revisão de literatura bibliográfica. Os dados extraídos na pesquisa foram a partir dos US National Library of Medicine (PubMed) com os descritores Teleradiology e Diagnostic Imaging, de acordo com os Descritores em Ciências da Saúde (DeCS). Para efetuar o cruzamento destes foi utilizado o operador booleano AND. Foram encontrados 704 artigos e após critérios de inclusão e exclusão, 13 artigos foram utilizados. Os utilizados para a inclusão: artigos em inglês, português ou espanhol, entre junho de 2015 a julho de 2021, e que estivessem disponíveis na íntegra e para acesso online grátis. Excluíram-se, os estudos que não abordassem o conceito relevante para o alcance do objetivo; estudos repetidos; segundo critérios de qualidade metodológica. Resultados: Os estudos de Almeida mostraram evolução nas rotinas operacionais de clínicas e hospitais que aderiram ao uso da telerradiologia. Cardoso elencou enormes benefícios para comunidades situadas em regiões mais afastada dos grandes centros desprovidas de acesso a saúde. Assim, foi constado uma grande necessidade dos profissionais buscarem por qualificações, aperfeiçoamentos e treinamentos de informática para manusear os equipamentos e sistemas com maior precisão. Conclusão: A telerradiologia tem apresentado inúmeras vantagens em sua aplicação, como auxilio diagnóstico a pequenas comunidades em regiões distantes dos grandes centros urbanos, além de fornecer imensos benefícios a clinicas e hospitais, carentes de mão de obra.

Descritores: Telerradiologia, Diagnóstico por Imagem 


\section{IMPORTÂNCIA DA TERAPIA NUTRICIONAL NO TRATAMENTO DE FÍSTULAS DIGESTIVAS}

Amanda Ferreira Garcia Queiroz, Leda Ferraz (orientador)

Categoria: Painel

Introdução: Fístulas digestivas são comunicações anormais entre duas superfícies epiteliais, em geral, entre o tubo digestivo e a pele. As fístulas também podem ser entendidas conforme a sua localização anatômica, ao débito, à origem ou ainda como primárias (processo patológico intestinal) ou secundárias (intervenções cirúrgicas). A predominância de desnutrição em paciente com fistula é de $30 \%$ a $78 \%$ dos casos, sendo que há uma direta relação entre elas, apresentando juntas maior perspectiva de complicações como sepse e retardo no fechamento da fistula. Nos anos 1950, a mortalidade associada à fístula pós-operatória variava de 40\% a 50\%, porém nos anos de 1960 e 1970 , diminuiu para $15 \%$ a $21 \%$ devido a inserção da terapia nutricional, sendo esta utilizada como cuidado nutricional logo após o diagnóstico de fistula digestiva. Objetivo: descrever a importância e características da terapia nutricional para o melhor tratamento e manejo dos pacientes acometidos pelas fistulas digestivas. Material e Método: Trata-se de uma pesquisa bibliográfica, do tipo revisão de literatura. Os artigos foram buscados nas bases de dados da Biblioteca Virtual em Saúde, Scielo e PubMed, utilizando os descritores: "fístulas do sistema digestório", "desnutrição" e "terapia nutricional". Foram incluídos trabalhos completos escritos no idioma português, entre os anos de 2011 a 2019. De acordo com os critérios de elegibilidade aplicados, foram utilizados 10 artigos publicados. Resultado: $O$ compilado de artigos aponta que a terapia nutricional deve ser individualizada, de acordo com a localização e o tipo da fistula. Em relação aos macros e micronutrientes da dieta a ser ofertada, as quantidades de calorias, lipídeos, proteínas, vitaminas e minerais são dependentes da presença de sepse e do débito da fistula. Somados a isto, é indicado também quantidades adequadas de água e eletrólitos. Essa terapêutica diminui o tempo de internação, das taxas de infecção, da taxa de mortalidade e ainda aumenta a incidência de fechamento de fistulas. Conclusão: A terapia nutricional deve ser indicada à pacientes com fístulas digestivas e ofertada de forma individualizada. Quando usada em conjunto ao tratamento médico, proporciona proteção ao prognóstico fatal.

Descritores: fístulas do sistema digestório, desnutrição, terapia nutricional 


\section{INCOMPETÊNCIA ISTIMOCERVICAL E SEU MANEJO}

Amanda dos Santos Hernandes, Fernanda Fávero, Stella De Paula Lima, Morisa Martins Leão Carvalho (Orientador)

Categoria: Painel

Introdução: A incompetência istmocervical (IIC) é uma condição em que há perda gestacional recorrente na forma de abortos tardios e/ou partos prematuros iniciados por cervicodilatação precoce, provocada por defeito local e não pela presença de contrações uterinas. Mulheres com esta doença apresentam clínica representativa, em que a dilatação do colo uterino não apresenta sintomas até que haja a rotura das membranas devida à exposição das mesmas ao ambiente vaginal, o que é seguido por trabalho de parto ou de abortamento rápido, pouco doloroso e sem sangramento expressivo. Apesar da criança nascer viva, há elevados indicativos de morbimortalidade devido a prematuridade. A fim de evitar este resultado, a cerclagem foi sugerida como tratamento capaz de evitar esta perda gestacional. Cerclagem significa sutura em bolsa e foi idealizada como maneira de manter o colo fechado, impossibilitando anatomicamente sua dilatação antes do final da gravidez, evitando, assim, o parto prematuro. Objetivo: Esse trabalho visa mostrar a importância da cerclagem como forma de tratamento para a incompetência istimocervical (ICC), além da sua eficácia em impedir a prematuridade. Relato de caso: M.E.D., 30 anos, com idade gestacional de 12 semanas, (G3/P0/A2). Durante a consulta teve diagnóstico de incompetência istmo cervical, verificado em seus antecedentes obstétricos, sendo indicado a cerclagem uterina. A mesma já havia apresentado dois abortos anteriores, o primeiro com IG de 21 semanas e o segundo com 18 semanas. Na gestação atual, foi realizada a cerclagem com 14 semanas. A gestante também utilizou progesterona durante 0 pré natal. Com 36 semanas foi retirada a cerclagem e supensa a medicação. O parto ocorreu com 38 semanas sem intercorrências. Conclusão: Nos casos de incompetência ístmo cervical, a associação de progesterona micronizada e a cerclagem, realizada na $14^{\underline{a}}$ semana, promovem o sucesso para uma gestação a termo.

Descritores: Incompetência istmo cervical, Cerclagem, Prematuridade 


\section{INDICAÇÕES DE CIRURGIA E TRATAMENTO CONSERVADOR PARA HÉRNIA DE DISCO LOMBAR: UMA REVISÃO DE LITERATURA}

Allana Caroline Viganó Brambila, Amanda Martins Pereira, Amanda O Spazini, Amanda Pinato Alves da Costa, Gabriela do Santos Romero, Letícia Passolongo Silva

Categoria: Painel

Introdução: A hérnia de disco é a projeção do núcleo pulposo para além de seus limites normais. Isto gera pressão sobre a raiz nervosa ocasionando dor. $30 \%-40 \%$ da população, sofre com ciatalgia a partir dos 40 anos de idade. A dor tende a piorar com manobra de Valsalva, além da capacidade de causar parestesia em segmento de dermátomo da raiz nervosa. Objetivo: esse trabalho visa estimar e comparar as indicações, riscos e benefícios pela escolha cirúrgica e/ou tratamento conservador, para reparação de hérnia de disco lombar, e comparar os resultados encontrados. Metodologia: o trabalho desenvolvido trata-se de um estudo realizado por meio de revisão bibliográfica com busca de literatura nas bases de dados BVS salud, PubMed e Cochrane, publicados no período de 2016 a 2021. O presente estudo discorre sobre as indicações e contraindicações cirúrgicas para correção da hérnia discal lombar. Consultado em setembro de 2021, foram excluídos do trabalho artigos incompletos ou inconclusivos. Resultados: Conforme descrito em literatura o tratamento conservador deve prevalecer em pacientes com dor há menos de seis meses, a prescrição em quadro agudo e para tratamento evidencia repouso, AINES, corticoides, injeções epidurais de esteroides, opioides, fisioterapia, pilates, há evidencias relacionadas à eficácia com tratamento por meio de medicina complementar e integrativa. Os sintomas de dor lombar podem minimizar, independente do tratamento, em até três meses. A correção cirúrgica é indicada em pacientes com defeito neurológico grave ou progressivo, bem como, disfunção sexual, síndrome da cauda equina, dor incapacitante e persistente, e alteração do esfíncter urinário. As vantagens do procedimento minimamente invasivo caracterizam-se em menores danos teciduais, além de tempo cirúrgico reduzido, sangramento em menor quantidade, índice de infecção baixo. As maiores desvantagens são em relação a técnica cirúrgica, sendo elas a limitação da mobilidade no interior do canal medular, custo elevado, dificuldade em nova operação devido fibrose e perda de parâmetros anatômicos. O sistema a vídeo apresenta menor dano traumático e menor morbidade. Se realizado com indicação correta, tende a proporcionar melhor qualidade de vida ao paciente. Conclusão: A cirurgia pode conceder alivio doloroso instantâneo, porem o índice de recidiva da dor, em geral, ocorre no limite de um ano e pacientes tendem a referir níveis de dor semelhantes a outros pacientes que não realizaram cirurgia, mas aderiram a tratamento conservadorista.

Descritores: Deslocamento do Disco Intervertebral; Tratamento Conservador; Cirurgia. 


\section{INJÚRIA RENAL AGUDA NO POLITRAUMATIZADO}

Amanda Oliva Spaziani, Everhton Paulo de Freitas Primo, Isadora Medrado Goulart, Letícia Okazaki Reis, Raissa Silva Frota, Rodolfo Alves e Silva

Categoria: Painel

Introdução: A Injúria Renal Aguda (IRA) é definida pela rápida queda na função renal, podendo ocasionar perda de parcela desse parâmetro nefrológico ou de sua totalidade. Tal síndrome está associada a importante aumento na morbimortalidade em curto e longo prazo. No contexto do paciente politraumatizado ocorre, na maioria das vezes, por uma conjuntura de fatores, resultando em redução abrupta da função renal, impossibilitando os rins de exercerem suas funções básicas; Objetivos: Este trabalho tem como objetivo identificar os fatores de risco para o desenvolvimento de injúria renal aguda em pacientes politraumatizados e sua influência na mortalidade. Métodos: Tratase de uma revisão bibliográfica de caráter analítico realizada por meio de pesquisas nas bases de dados SciELO, PubMed e Google Acadêmico utilizando os descritores "injúria renal aguda" e "politraumatizado". Foram encontrados 783 artigos e após critérios de inclusão e exclusão, 11 foram selecionados. Utilizou-se os seguintes critérios para inclusão: artigo em português e inglês entre o período de 1999 até 2019, disponíveis na íntegra, acesso gratuito e online. Os critérios de exclusão foram artigos que não abordassem o tema para alcance de objetivo e estudos repetidos. Resultados: A partir dos dados analisados, a mortalidade, o tempo de internação e a necessidade de UTI foram consideravelmente maiores nos pacientes que desenvolveram lesão renal aguda (LRA), aumentando 7,5 vezes o risco de óbito (BAITELLO, et.al., 2013). O desenvolvimento de IRA no paciente politraumatizado é, geralmente, multifatorial, envolvendo fatores relacionados à ressuscitação volêmica inicial, ao grau de resposta inflamatória sistêmica associada ao trauma, ao uso de contraste iodado para procedimentos diagnósticos, à rabdomiólise e à síndrome compartimental abdominal (ROMANO, et.al., 2013). Conclusão: Levando em consideração esses aspectos, o paciente politraumatizado está exposto a inúmeros fatores de risco para o desenvolvimento de IRA, sendo de suma importância a formulação de estratégias de atendimento destes pacientes vítimas de trauma grave, visando à prevenção da IRA e da elevada mortalidade. Diversos estudos observaram que quanto mais segmentos corporais comprometidos pelo trauma, maior será a predisposição para desenvolvimento de LRA, devido a hipovolemia, alterações metabólicas e inflamatórias decorrentes do trauma grave.

Descritores: injúria renal aguda, politraumatizado, mortalidade. 


\section{MANEJO DA COLITE ULCERATIVA AGUDA GRAVE}

Everhton Paulo de Freitas Primo, Isadora Medrado Goulart, Luana Martins Camilo, Miguel Pereira Goulart Neto, Natália Inácio Beltramini, Raissa Frota

Categoria: Painel

Introdução: A colite ulcerativa aguda grave (ASUC) é emergência médica e seu manejo permanece ainda um desafio. Para sua definição, são considerados: diarreia, sangramento anal, febre, taquicardia, anemia. É caracterizada por processo inflamatório crônico do cólon e reto, com extensão e gravidade variáveis. Aproximadamente $20 \%$ dos pacientes com colite ulcerosa apresentam um surto severo. O tratamento tem como objetivo induzir a remissão clínica, a diminuição da morbimortalidade e a melhoria na qualidade de vida. Para isso, é importante a abordagem multiprofissional com atitude proativa e medicação adequada. Objetivo: Este trabalho tem como objetivo revisar a literatura científica em relação ao manejo da colite ulcerativa aguda grave. Material e Método: Consiste em uma revisão de literatura bibliográfica. Os dados foram extraídos da PubMed com os descritores: Management, Colitis, Ulcerative e Severe, através do operador booleano AND. Foram encontrados 593 artigos e após critérios de inclusão e exclusão, 06 artigos foram utilizados. Os critérios de inclusão foram artigos em inglês e espanhol entre 2015 a 2021 disponíveis online na íntegra. Excluíram-se os estudos que não abordassem o conceito relevante, estudos repetidos e segundo qualidade metodológica. Resultados: O tratamento da ASUC tem evitado a colectomia na maioria dos casos, desde que iniciado precocemente e com acompanhamento multidisciplinar. Os pacientes devem fazer uma avaliação clínica diária. Dessa forma, exame físico, hemograma, avaliação hemodinâmica e nutricional, gráficos de fezes, eletrólitos, PCR, radiografia abdominal, sigmoidoscopia flexível não preparada devem ser considerados. A maioria dos pacientes necessitará de fluidos intravenosos com correção do desequilíbrio eletrolítico. As infecções devem ser excluídas e a tromboprofilaxia, iniciada. Os corticosteroides intravenosos são o tratamento de primeira linha. $O$ tratamento de resgate com ciclosporina ou infliximabe é indicado em pacientes que não respondem aos corticosteroides. Caso a terapia médica ainda não seja suficiente, a colectomia deve ser realizada para evitar complicações críticas. Conclusão: Portanto, a ASUC é uma emergência médica que requer tratamento imediato e multidisciplinar. A avaliação inicial é crítica e, embora as taxas de colectomia tenham reduzido, a necessidade de procedimentos urgentes não diminuiu. Isso indica uma grande necessidade de melhorar os cuidados gerais em pacientes que apresentam a doença.

Descritores: Management, Colitis, Ulcerative, Severe. 


\section{MANEJO DO PNEUMOTÓRAX OCULTO}

Carolina Maciel Sales, Marina Toso, Monick Buosi dos Santos

Categoria: Painel

Introdução: O pneumotórax é definido como uma coleção de ar na cavidade pleural, sendo grande parte dos casos relacionados ao trauma torácico. Quando uma coleção de ar dentro da cavidade pleural não é encontrada por raio-x de tórax póstero-anterior convencional, mas sim na tomografia computadorizada (TC) de tórax, denomina-se pneumotórax oculto. O tratamento tradicional de pneumotórax pós-traumático simples detectado por clínica e raio-x póstero-anterior é a toracostomia, mas nem todos requerem essa conduta, o que torna o tratamento do pneumotórax oculto polêmico e debatido por especialistas, entre a gestão expectante e a colocação do tubo torácico. Objetivo: coletar dados atuais de diagnóstico e melhor conduta perante o pneumotórax oculto de pacientes traumatizados, selecionar e enfatizar a melhor abordagem para esta patologia através da revisão bibliográfica. Material e Método: O presente artigo foi elaborado a partir de uma revisão bibliográfica por estudo retrospectivo, nas bases de dados PubMed, Lilacs e Google Acadêmico, utilizando artigos no período de 2016 a 2021. ResultadosA partir da análise dos artigos selecionados observou-se que em sua maioria, os casos de pneumotórax oculto são identificados com o uso da tomografia computadorizada de tórax em comparação a radiografia. A conduta para manejo do pneumotórax ainda é um tema controverso, o tratamento conservador é muito defendido e ratificado em pacientes hemodinamicamente estáveis e que não recebem ventilação mecânica. Em pacientes submetidos à ventilação mecânica, a toracostomia é aconselhada para prevenir desenvolvimento de pneumotórax de tensão. Assim como em pacientes que apresentam pneumotórax volumoso, presença concomitante de hemotórax, instabilidade hemodinâmica. Conclusão: Conclui-se, portanto, que a TC de tórax é o exame padrão-ouro no diagnóstico de pneumotórax oculto. A terapêutica conservadora é a mais apropriada nos casos estáveis, seguida de acompanhamento clínico. A intervenção estará indicada naqueles pacientes que apresentarem sinais e/ou sintomas de instabilidade mediante observação e quando evoluírem com necessidade de suporte ventilatório devido ao pneumotórax.

Descritores: Pneumotórax, pneumotórax oculto, pacientes traumatizados. 


\section{MEDIDAS ADOTADAS PARA O ENFRENTAMENTO DA COVID-19 NA UNIDADE DE PRONTO ATENDIMENTO NO NOROESTE PAULISTA}

Isadora Medrado Goulart, Matheus Alves de Souza, Miguel Pereira Goulart Neto, José Martins Pinto Neto (orientador)

Categoria: Painel

Introdução: O conceito de pandemia é aplicado a partir do momento em que determinada doença tem sua incidência elevada de maneira abrupta e repentina e passa a ser disseminada em outras áreas geográficas além da inicial. Em 2020 a população mundial vivenciou a mais recente pandemia registrada, denominada de Coronavírus 2019 (COVID-19). Desse modo, tem sido uma ameaça potencial à saúde humana, despertando atenção global após vivenciar uma ampla disseminação da doença, visto sua alta virulência e transmissibilidade. O surgimento deste patógeno destacou a importância da utilização de equipamentos de proteção individual, bem como de medidas básicas como a higienização das mãos. Objetivos: Identificar, descrever e analisar as medidas de biossegurança e o estado de saúde mental dos Médicos da Unidade de Pronto Atendimento para o controle da pandemia de COVID-19 num município, do noroeste paulista, no período de maio a agosto de 2021. Metodologia: Trata-se de um estudo descritivo, transversal, com abordagem quantitativa. O presente projeto foi submetido à aprovação do Comitê de Ética em Pesquisa destinado pela Plataforma Brasil sob o número CAEE: 34860720.0.0000.5472. Resultados: com base nos resultados obtidos por meio da coleta de dados, pode-se observar que todos os médicos abordados se autodeclaram de raça/cor branca. Além disso, $90 \%$ identificam-se em sexo feminino e $10 \%$ em sexo masculino. De acordo ao tempo do término da graduação $50 \%$ formaram de 6 a 10 anos, $40 \%$ de 1 a 5 anos e $10 \%$ de 11 a 21 anos. Em relação à utilização de Equipamento de Proteção Individual, esse grupo mostrou-se satisfatório perante o uso de máscara cirúrgica e máscara N95/PFF2, já os itens óculos de proteção e face shield não foram utilizados na maioria dos casos. Além disso, fica evidente que a saúde mental dos profissionais de saúde está afetada devido ao momento crítico vivenciado. Conclusão: nessa pesquisa foi possível identificar que a maioria dos médicos adotam medidas de biossegurança durante o exercício das suas atividades profissionais, no entanto, algumas destas medidas, recomendadas pelo Ministério da Saúde, não estão sendo seguido por estes profissionais, o que reforça a necessidade de educação permanente para estes profissionais do SUS. Por fim, vale ressaltar que por se tratar de um momento crítico e duradouro a saúde mental dos profissionais está deteriorada, gerando cada vez mais preocupações e problemas psicológicos.

Descritores: Infecções por coronavírus, Isolamento social, Pandemias. 


\section{MICROANGIOPATIA CEREBRAL ASSOCIADA À FATORES DE RISCO: UM RELATO DE CASO}

Fernando Augusto Soranz, Giovanna Fiorindo Soranz, Monic Rondina Fontes, Vinicius Paiva Gontijo, Vinicius Salgado Marques

Categoria: Painel

Introdução: A presença de diabetes mellitus, hipertensão arterial, são de alta incidência na população brasileira e é um fator de risco ligado a uma variedade de fatores vasculares, neste relato de caso vemos a influência da diabetes mellitus, hipertensão arterial sistêmica em correlação a lesões infectadas após queda da própria altura concomitante á alterações neurológicas. Objetivo: Apresentar o relato de caso com sinais e sintomas característicos de AVC, porém, sem o acontecimento de tal acidente, sendo correlacionado a outros achados clínicos. Relato De Caso: Paciente J.R.L., 55 anos, com admissão no Hospital Municipal Dr. Lauro Roberto Fogaça no município de Votorantim-SP com queda da própria altura devido a ingesta de bebida alcoólica. Apresentou lesão corto contuso na cabeça, mas sem perca de consciência. Ferida estava aberta e exposta, pois encontrava-se há 6 dias sem sutura e cuidados. Exames laboratoriais da admissão indicaram leucócitos de $10400 \mathrm{~mm}^{3}$, hemoglobina de $8,6 \mathrm{~mm}^{3}$ e proteína C reativa de $48 \mathrm{mg} / \mathrm{L}$. Evoluiu com quadro de febre e secreção purulenta. Ao longo dos dias, começou a apresentar astenia em hemicorpo esquerdo, sendo que, não apresentava tais alterações antes do fato. Para investigação foi realizado tomografia computadorizada de crânio, 5 dias após admissão em enfermaria e avaliação neurológica e neurocirúrgica. Após avaliação neurocirúrgica e tomográfica, evidenciou ausência de alterações traumáticas e isquêmica que explicassem tais sinais. Apesar de apresentar aumento de partes moles parietal alta direita, nenhum dos outros achados foram sugestivos à Neurocirurgia para astenia à esquerda o que levou mais a fundo a investigação do caso. Notou-se uma microangiopatia cerebral, relacionado a rarefação de mielina e ao antecedente pessoal de etilismo grave, diabetes mellitus, hipertensão arterial sistêmica e tabagismo, todos fatores de risco a gliose. Sendo assim, chegou-se à correlação de todos achados, junto ao trauma corto contuso com aumento de partes moles à direita, desta possível causa para a astenia em hemicorpo esquerdo. Conclusão: Chegouse à conclusão de não ser um caso de acidente vascular encefálico, mas sim como fator desencadeante o trauma por queda da própria altura. Uma causa que pode estar relacionado aos fatores de risco como tabagismo, etilismo, dislipidemia, diabetes mellitus que levaram a microangiopatia cerebral, gliose e sendo agravado com a lesão corto contuso sem tratamento prévio devido ao trauma.

Descritores: Microangiopatia Cerebral, Astenia, Fator de Risco. 


\section{MICRORGANISMOS PRESENTES NOS ESTETOSCÓPIOS DE PROFISSIONAIS DA SAÚDE}

Luísa Masson Francisco, Dora Ines Kozusny-Andreani (Orientadora)

Categoria: Apresentação Oral

Introdução: As infecções relacionadas à assistência à saúde (IRAS) são motivo de preocupação em ambientes hospitalares por possuírem um prognóstico ruim. Essas infecções, muitas vezes, são transmitidas pelos profissionais ou pelos instrumentos de trabalho, por infecção cruzada. Uma dessas ferramentas são os estetoscópios que entram em contato direto com a pele do paciente, havendo necessidade de desinfeta-los após sua utilização, o que, geralmente, não ocorre. Objetivos: Objetivou-se realizar uma busca ativa por microrganismos potencialmente patogênicos presentes nos estetoscópios dos profissionais da área da saúde de um hospital do Noroeste Paulista. Metodologia: Trata-se de um estudo transversal, analítico e quantitativo, em que foram coletadas 60 amostras por meio de swabs esterilizados, passando-os nos diafragmas dos estetoscópios dos profissionais da saúde. As amostras foram semeadas e inoculadas em meios de cultura contendo caldo BHI (Brain Heart Infusão) incubados por 24 horas em uma incubadora aeróbica em $35^{\circ} \mathrm{C} \pm 1$. Após a incubação, 0,050 microlitros das amostras foram inoculados em Agar Triptecaseina soja (TSA), manitol de sal ágar (SM) e Agar eosina- azul de metileno (EMB), incubados por 24-48 horas, em aerobiose a $35^{\circ} \mathrm{C} \pm$ 1. As culturas positivas foram avaliadas pelo método de coloração de Gram. As colônias Grampositivas foram submetidas às provas bioquímicas de fermentação de manitol, catalase e coagulase e para as Gram-negativos, foi utilizado o método bioquímico padrão para identificação: fermentação oxidativa glicose, citrato de Simmons, caldo de arginina, descarboxilase e motilidade de lisina e ornitina. Resultados: Verificou-se que das 60 amostras colhidas, 46 apresentaram crescimento microbiano; e todas as amostras positivas foram contaminadas por bactérias Gram-positivas (Staphylococcus, Micrococcus, Streptococcus, Bacillus, Propionibacterium acnes e Enterococcus), sendo Staphylococcus aureus mais prevalente $(65,22 \%)$. Apenas 4 amostras estavam contaminadas por Gram-negativas (Escherichia coli e Pseudomonas aeruginosa). O problema de o S. aureus ter sido o preponderante é que tem potência para se tornar resistente aos tipos de antibióticos do ambiente hospitalar, resultando em um patógeno capaz de causar doenças relacionadas à assistência à saúde. Conclusão: Desse modo, higienizar as mãos e desinfectar objetos de uso profissional são etapas básicas que não devem ser puladas em ambientes hospitalares para que se possa evitar uma IRAS.

Descritores: Estetoscópio, Microrganismos, Hospitalar 


\section{MONITORAMENTO DE SARS-COV-2 EM ESGOTO E O SANEAMENTO BÁSICO NO ENFRENTAMENTO DA PANDEMIA DE COVID-19}

Elise Baroni Ramos, Everhton Paulo De Freitas Primo, Noelen Muriel Doimo Prado Martins, Juliana Heloisa Pinê Américo-Pinheiro (Orientadora)

Categoria: Apresentação Oral

Introdução: A COVID-19 é uma doença infecciosa causada pela nova cepa do coronavírus (SARSCoV-2) e sua transmissão ocorre, principalmente, pela via respiratória. A presença de sintomas como náuseas, vômitos e diarreia, referente à infecção das células do trato gastrointestinal pelo vírus, pode favorecer a presença de partículas viáveis de SARS-CoV-2 na excreção fecal e subsequente contaminação dos esgotos. Dentre as recomendações da Organização Mundial da Saúde para proteção contra o vírus, lavar as mãos frequentemente é a medida mais comprometida ao se considerar às fragilidades sócio estruturais do acesso à água e ao saneamento básico em algumas regiões do Brasil. Aproximadamente $50 \%$ do esgoto sanitário é coletado e tratado no Brasil, variando entre os extremos de $12 \%$ na região Norte e $79,5 \%$ na região Sudeste. Objetivo: Realizar uma revisão de literatura de estudos sobre a presença de SARS-CoV-2 no esgoto, sua relação com o acesso às condições básicas de saneamento e a relevância do monitoramento do vírus nas redes de esgoto como ferramenta de auxílio na contenção da disseminação viral. Metodologia: Foi utilizado para a pesquisa a plataforma Google Acadêmico, tendo como critério publicações de revistas científicas em língua portuguesa entre 2020 e 2021, com as palavras-chaves COVID-19 e esgoto. Resultado: Foram selecionados oito artigos, dos quais três avaliaram a relação entre a incidência de COVID-19 e as condições do saneamento básico e cinco fundamentaram-se em revisões de literatura nacionais e internacionais. A presença de partículas do vírus pode ser monitorada em esgotos utilizando-se um método em que o RNA viral é detectado por meio da amplificação do ácido nucleico pela reação em cadeia da polimerase (RT-PCR). Assim, há uma relação inversamente proporcional, em que quanto maior a proporção da população com acesso a coleta e tratamento de esgoto, menor é a taxa de incidência da contaminação pelo SARS-CoV-2. O monitoramento do vírus nas redes de esgoto para o acompanhamento da circulação do SARS-CoV-2 e o estabelecimento de escalas de surto da infecção mostraram ser medidas efetivas para implementação de ações de suporte e contenção do vírus. Conclusão: $O$ saneamento básico é condição essencial para enfrentamento da pandemia de COVID-19, assim como o monitoramento para auxílio na detecção e contenção da disseminação do vírus.

Descritores: infecções, saúde ambiental, vírus. 


\section{NOVO FINANCIAMENTO DA ATENÇÃO BÁSICA: PANORAMA HISTÓRICO E ANÁLISE DO MUNÍCIPIO DE FERNANDÓPOLIS-SP}

Isabela Spinola Luro, Isadora Toledo Saes Lopes, Luana Teixeira Kol, Flávio Carlos Ruy Ferreira (orientador)

Categoria: Apresentação Oral

Introdução: A história da saúde no Brasil passou por diferentes modelos até a criação do Sistema Único de Saúde (SUS). Ao longo de três décadas de SUS, o Brasil enfrenta dificuldades na gestão e execução dos serviços de saúde. O acesso ao histórico de transferência aos municípios, vinculada ao conhecimento de gestões anteriores, facilita a compreensão acerca dos impactos dos diferentes modelos de financiamento. Objetivo: $O$ presente trabalho visa analisar os repasses feitos ao município de Fernandópolis nos últimos dez anos; e explanar sobre as mudanças de financiamento do SUS, em especial, o Programa Previne Brasil. Material e Método: Revisão de literatura através das bases de dados da BIREME e da SciELO, utilizando os descritores de assunto "Atenção Básica à Saúde", "Atenção Primária à Saúde", "Financiamento"; "SUS"; consulta da legislação e regulamentação do SUS em sites do Ministério da Saúde; e recrutamento dos repasses ao ente municipal, ao longo dos últimos 10 anos, no Fundo Nacional de Saúde e e-gestor AB. Resultados: A nova Portaria, no 2.979/19, altera o método que determina os valores de repasse federal ao bloco de Custeio na Atenção Primária à Saúde, o qual passa a ser composto por 3 critérios: Capitação Ponderada, Pagamento por Desempenho e Incentivo às ações estratégicas. Além disso, a reavaliação desses critérios será de forma quadrimestral. Com o novo modelo, não haverá mais o Piso da Atenção Básica (PAB) fixo; o repasse será proporcional à população adscrita nas equipes de saúde e aos determinantes de vulnerabilidade e tipologia da região. A análise do FNS mostra ascensão do repasse ao bloco Custeio, grupo Atenção básica, desde 2016; com aumento acentuado em 2018 e 2019, e aumento discreto em 2020, ano em que não há mais o repasse do PAB fixo, substituído pelo "per capita de transição" que permaneceu em vigor a fim de facilitar a implementação do Previne Brasil. Conclusão: Os achados desta revisão identificaram um aumento progressivo, nos últimos 10 anos, dos repasses ao bloco de Custeio grupo AB, em Fernandópolis-SP. Ao longo dos anos, observou-se maior flexibilidade da autonomia municipal. Os efeitos municipais do Previne Brasil ainda não foram notados, considerando a complexidade e os impactos oriundos da COVID-19. Espera-se um acréscimo da cobertura de pessoas cadastradas e fortalecimento da eSF e das equipes da APS, mas resultados só serão observados de fato, a partir do próximo ano.

Descritores: Financiamento da Saúde, Sistema Único de Saúde (SUS), Atenção Primária em Saúde 


\section{O POTENCIAL DA VITAMINA D EM TEMPOS DE COVID-19}

Fernando Ribeiro Oliveira Avi, Laís Joverno Domingues, Larissa Leslye Ribeiro, Luísa Masson Francisco, Nathália Martins Sonehara (orientadora)

Categoria: Apresentação Oral

Introdução: Em pouco tempo uma doença infecciosa viral, causada pelo SARS-CoV-2, foi exposta ao mundo como COVID-19. Desde então, gerou um grande interesse aos pesquisadores, que buscam elucidar os mecanismos de infecção que levam à disseminação e expressão desta doença, quanto aos possíveis fatores de risco que podem estar correlacionados com a propagação ou controle da patologia. Assim, a vitamina $D$, hormônio que atua na absorção de cálcio, surgiu como um fator que pode se relacionar com as duas esferas citadas. Objetivo: $O$ trabalho buscou compreender a correlação entre os níveis de vitamina $D$ e o prognóstico de pacientes com COVID-19. Material e Método: Trata-se de uma revisão de literatura indexada através da utilização das plataformas de dados Scielo, Pubmed e Biblioteca Virtual da Saúde, utilizando os descritores Vitamina D e COVID19. Os critérios de inclusão abrangem artigos na língua portuguesa e inglesa, publicados entre 2020 e 2021. Resultado: Estudos demonstram que a vitamina D pode alterar a susceptibilidade ao SARSCoV-2 e a progressão da doença, atuando principalmente na redução do risco de adquirir a infecção e a replicação viral. Evidências destacam também, o importante papel desse hormônio na diminuição da produção de citocinas pró-inflamatórias e metaloproteinases, redução das concentrações da enzima conversora de angiotensina 2 e da bradicinina, além de atuar na manutenção da integridade endotelial. Isto posto, a vitamina $D$ pode diminuir a severidade da doença, colaborando de maneira anti-inflamatória, antioxidante e moduladora do sistema imune, reduzindo os riscos do avanço da infecção. Conclusão: Diante do exposto, as evidências dos estudos sugerem o papel da vitamina $D$ na patogenia da COVID-19, contribuindo na diminuição dos fatores de risco e no melhor desfecho clínico dos pacientes infectados. No entanto, devemos ressaltar a importância da realização de mais estudos clínicos a fim de melhor elucidar a relação entre a vitamina D e o COVID-19.

Descritores: COVID-19, Vitamina D; Prognóstico 


\section{PADRÃO E NECESSIDADE DO ATENDIMENTO PRÉ - HOSPITALAR PARA IDOSOS}

Amanda Oliva Spaziani, Luana Martins Camilo, Micaelly Silva de Camargo, Mylena Aparecida Silva de Camargo, Natália Inácio Beltramini, Raissa Silva Frota

Categoria: Apresentação Oral

Introdução: $O$ atendimento inicial de pacientes críticos idosos é realizado fora do ambiente hospitalar, em caráter de urgência. Em curso do envelhecimento da população, geraram novas demandas para o atendimento. Os idosos possuem uma vasta rede de peculiaridades, levando a maior utilização de serviços de alta complexidade. Objetivos: Realizar uma revisão sistemática frente ao padrão e necessidade do atendimento pré-hospitalar para os idosos. Métodos: Trata-se de uma revisão bibliográfica de caráter analítico realizada por meio de pesquisas nas bases de dados SciELO e Google Acadêmico por meio das palavras-chaves: "idosos", "atendimento pré-hospitalar" e "trauma". Foram encontrados 60 artigos e após critérios de inclusão e exclusão, 16 artigos foram selecionados. Utilizou - se os seguintes critérios para inclusão: artigo em português e inglês, entre o período de 2004 até 2021, disponíveis na íntegra, acesso gratuito e online. E os critérios de exclusão foram artigos que não abordassem o tema para o alcance de objetivo e estudos repetidos. Resultados: Os traumas na população idosa ocorrem em decorrência da exposição a fatores de risco, como síndrome da fragilidade, comorbidades, polimedicação, entre outros. No atendimento de emergência, os idosos recebem as recomendações do ATLS (Advanced trauma Life Support). Devese levar em consideração as modificações morfológicas e funcionais que ocorrem devido ao avançar da idade, como do sistema neurológico. Na etapa de via área e controle da coluna cervical os idosos ficam vulneráveis à aspiração de fluidos e outros objetos sólidos. Durante a respiração e ventilação, realiza avaliação respiratória, ausculta, palpação e percussão, é comum que possuam dispneia e hipóxia, e necessitem de suporte ventilatório. $\mathrm{Na}$ avaliação da circulação se inclui a qualidade, frequência e regularidade do pulso, avaliação de possíveis sinais de choque, perfusão periférica e hemorragias externas. E avaliação neurológica é realizado de forma rápida pelo método AVDN (alerta; verbal; dor e não responde). E em exposição procura-se outras lesões que estabelecem necessidades de cuidado na exposição do idoso durante toda avaliação. Conclusão: Portanto, o crescimento da população idosa e as ocorrências de natureza traumática, representam novos desafios para os serviços de urgência e emergência. É necessário ter em mente todas as alterações do processo de envelhecimento para que seja realizado o atendimento de forma adequada.

Descritores: idosos; atendimento pré-hospitalar; trauma. 


\section{PERFIL EPIDEMIOLÓGICO DOS CASOS CONFIRMADOS DE SÍNDROME DA IMUNODEFICIÊNCIA HUMANA (AIDS) NO ESTADO DE MINAS GERAIS}

Anessa Tiemi Yoshida, Gabriela da Silva Cruz, Matheus Alexandre da Silva Taliari, Danila Fernanda Rodrigues Frias (orientadora)

Categoria: Painel

Introdução: Vírus da Imunodeficiência Humana (HIV) causador da Síndrome da Imunodeficiência Humana (AIDS) promove grande impacto na saúde pública, pois é uma zoonose reemergente que faz vítimas no mundo todo desde a década de 80 . Em 2020, estimou-se que 37,6 milhões de pessoas estavam vivendo com HIV no mundo e $73 \%$ tinham acesso à terapia antirretroviral. No Brasil o número de casos de AIDS tem apresentado queda desde 2013, porém, a taxa de soropositividade em jovens entre 15 e 24 anos está aumentando a níveis alarmantes. Para o controle do avanço da doença, ações educativas de cunho coletivo devem ser discutidas e executadas, e para isso, pesquisas epidemiológicas sobre a doença são fortes aliadas para obtenção do sucesso destas ações. Objetivo: a presente pesquisa teve por objetivo descrever o perfil epidemiológico dos indivíduos HIV positivos no estado de Minas Gerais de 2010 a 2020. Metodologia: realizou-se um estudo transversal, descritivo, retrospectivo e qualiquantitativo com dados secundários coletados de 2010 a 2020 do site TABNET/DATASUS. As informações coletadas foram: número total de casos confirmados no estado, faixa etária, raça, sexo, tipo de transmissão, faz uso de drogas injetáveis, categoria de exposição e evolução do caso. A análise dos dados se deu por meio de estatística descritiva. Resultados: foram confirmados 47.306 casos de AIDS no estado de Minas Gerais no período estudado. O perfil dos indivíduos acometidos caracterizou-se por, $73,5 \%$ do sexo masculino, $38,3 \%$ raça branca, e 33,6\% possuíam entre 25 e 34 anos de idade. Com relação a transmissão 0,9\% foi vertical. Apenas $2,6 \%$ dos indivíduos relataram fazer uso de drogas injetáveis, $44,5 \%$ eram heterossexuais e $30,9 \%$ homossexuais. A taxa de letalidade do período foi de $7,37 \%$. A pesquisa permitiu concluir que o perfil dos indivíduos acometidos pelo HIV no estado de Minas Gerais de 2010 a 2020 trata-se de homens, heterossexuais, brancos e jovens (entre 25 e 34 anos de idade). Pelo fato de baixa quantidade de indivíduos relatarem uso de drogas injetáveis e pela caracterização dos acometidos, acredita-se que a propagação da doença esteja relacionada a prática de relações sexuais sem utilização de preservativos. Conclusão: medidas educativas devem ser realizadas de forma mais incisiva relacionadas a prevenção da doença, pois trata-se de uma afecção incurável e que apresentou taxa de letalidade considerável no estado de Minas Gerais.

Descritores: HIV, Saúde Única, Zoonose 


\section{PRESENÇA DE BACTÉRIAS POTENCIALMENTE PATOGÊNICAS AOS ANTIBIÓTICOS RESISTENTES EM SUPERFÍCIES DE UNIDADE BÁSICA DE SAÚDE}

Isadora Medrado Goulart, Matheus Alves de Souza, Miguel Pereira Goulart Neto, Dora Inês KozusnyAndrean (orientadora)

Categoria: Painel

Introdução e Objetivo: As superfícies de unidades básicas de saúde são apontadas como possíveis meios de contaminação e disseminação de bactérias e/ou fungos, provocando infecções. Os centros de saúde oferecem uma via de transmissão favorável para a disseminação desses patógenos devido às práticas inadequadas de controle de infecção entre os profissionais de saúde, os meios inanimados os quais os cercam, bem como a superlotação de pacientes. Além disso, esses organismos adquiridos em unidades básicas de saúde são, geralmente, resistentes a muitos antibióticos comuns. Material e Método: Os materiais e métodos são divididos em local da pesquisa e obtenção de amostras e provas de suscetibilidade a antimicrobianos. Na pesquisa realizada, realçou-se a presença de bactérias a partir de sete coletas das superfícies, correspondendo às áreas de maçaneta, colchão, mesa da enfermaria, assoalho do banheiro dos usuários do serviço e pia do banheiro dos usuários do serviço e, a partir disso, foi analisada a eficácia de antibióticos capazes de combatê-las. Essas coletas correspondem aos meses de Setembro, Outubro, Novembro, Dezembro de 2020, Janeiro, Fevereiro e Março de 2021. Resultados: A partir da análise do estudo realizado, foi encontrada a presença de Staphylococcus aureus em maçaneta, colchão e mesa da enfermaria; Staphylococcus epidermidis, em maçaneta e mesa da enfermaria; Escherichia coli, em colchão, assoalho do banheiro e pia do banheiro dos usuários do serviço e, por fim, Pseudomonas aeruginosa, em assoalho do banheiro e pia do banheiro. Além disso, com base na análise da resistência e susceptibilidade desses microrganismos aos antibióticos, foi observado, em seus valores absolutos, que a Escherichia coli apresenta-se 100\% susceptível ao Trimetoprim e $85 \%$ resistente ao Cloranfenicol; a Pseudomonas aeruginosa, 100\% resistente à Ampicilina; a Staphylococcus aureus, 100\% resistente à Ampicilina e Clindamicina e 100\% susceptível ao Trimetoprim e Canamicina e, por último, a Staphylococcus epidermidis, $85 \%$ resistente à Amicacina e $100 \%$ susceptível à Enrofloxacina. Conclusão: Com isso, foi possível confirmar a contaminação de superfícies de unidades básicas de saúde e a resistências dos microrganismos em relação ao fármaco. Assim, os antibióticos irão selecionando as bactérias e provocando infecções cada vez mais fortes. Essas evidências reforçam a necessidade de conhecimento e controle mais rigoroso de fontes de patógenos no serviço de saúde.

Descritores: Microrganismos, Bactérias, Unidades Básicas de Saúde. 


\section{PREVALÊNCIA DE DISGEUSIA E ANOSMIA EM PACIENTES COM COVID-19: UMA REVISÃO DE LITERATURA}

Giselle Juliana de Jesus, Janayne Fernandes da Silva, Jane Silvia Cardoso, José Antonio Santos Souza (Orientador)

Categoria: Painel

Introdução: Desde dezembro de 2019, a população mundial vem sofrendo com a infecção ocasionada pelo vírus SARS-CoV-2. Essa doença pode ocasionar desde sintomas leves até uma síndrome respiratória grave. Os pacientes podem apresentar anosmia e/ou disgeusia, sendo a primeira pela ação viral ao epitélio olfatório utilizando receptores da Enzima Conversora de Angiotensina 2 ou até por ataque direto nos neurônios olfativos, e a segunda por acometer células epiteliais que revestem os ductos das glândulas salivares alterando a sensação gustativa. Objetivo: o objetivo do presente trabalho foi verificar a prevalência de disgeusia e anosmia em indivíduos acometidos pela COVID-19. Materiais e métodos: Foi realizada uma revisão de literatura utilizando as seguintes Bases de Dados: PubMed, Biblioteca Virtual em Saúde e SciELO. Os critérios de inclusão foram: artigos em inglês, português ou espanhol, publicados nos últimos 5 anos, e como critério de exclusão estudos que não abordassem o tema proposto. Nesse trabalho, 9 artigos foram selecionados. Resultados: Um estudo observou que a anosmia (96\%) foi mais comum do que a disgeusia (75\%) em pacientes com a COVID-19. Em outro estudo, a prevalência de anosmia, disgeusia e juntos foi, respectivamente, $77 \%, 77 \%$ e $83 \%$. Outro estudo, mostrou que a anosmia foi 10,2 vezes mais prevalente em pacientes com COVID-19 em comparação com aqueles com doença semelhante a COVID-19, e que a anosmia e disgeusia têm valor preditivo de $82,5 \%$ para SARS-CoV2 RT-PCR positivo. Verificou-se também, que a anosmia em pacientes com COVID-19 variou com base na etnia; em caucasianos, por exemplo, é três vezes mais prevalente do que na população asiática. Os sintomas da anosmia desaparecem em 1-2 semanas, podendo ser persistente após 2 anos de contaminação. De modo geral, a recuperação das funções sensoriais é completa em $66 \%$ dos pacientes, sendo em menos de cinco dias e 34\% informaram persistência dos sintomas. Conclusão: Pode-se concluir que, a anosmia e a disgeusia são encontradas na maioria dos indivíduos acometidos pelo SARS-CoV-2 e muitas vezes são sintomas que precedem a doença clínica. Ademais, a anosmia pode ser um indicador potencial de infecção por SARS-CoV-2 e pode ser útil para o rastreamento e identificação precoce de pacientes com COVID-19. Embora a anosmia e a disgeusia são achados frequentes entre os pacientes com COVID-19, mais estudos precisam ser realizados a fim de definir tais sintomas como preditores do agravo.

Descritores: Anosmia. Disgeusia. COVID-19. 


\section{PUBERDADE PRECOCE CENTRAL CAUSADA POR DOENÇA DE FAHR: RARO RELATO DE CASO}

Bruno Antunes Contrucci, João Jorge Bizio Neto, João Victor Cóllo, Julia Medina Presente, Julia Moraes e Castro, Matheus Rodrigues Zorzetti

Categoria: Apresentação Oral

Introdução e Objetivo: A doença de Fahr é neurológica, rara, degenerativa, decorrente de calcificações não explicadas dos gânglios da base e núcleos subtalâmicos causando sintomas motores e comportamentais com clínica variável, conforme sua extensão topográfica. A puberdade precoce central (PPC), caracterizada pelo surgimento prematuro de caracteres sexuais secundários a partir da ativação do eixo hipotalâmico-hipofisário-gonadal, pode ser consequência de anormalidades no sistema nervoso central, sendo raramente relatada sua associação com doença de Fahr. Os autores buscaram relatar a associação entre puberdade precoce central e doença de Fahr, diagnosticada tardiamente em adolescente. Relato de caso: G.C.S, sexo feminino, 12 anos de idade, procedente de outro estado, apresentou quadro de aparecimento de pelos axilares e pubianos e de broto mamário desde os primeiros anos de vida com evolução insidiosa. Ademais, responsável refere haver atraso global do desenvolvimento neuropsicomotor presente, com perda de marcos no desenvolvimento, porém não investigado. Aos 5 anos de idade, apresentou quadros recorrentes de crise convulsiva do tipo tônico-clônica generalizada com eversão ocular e sialorreia de curta duração, sendo introduzido anticonvulsivante desconhecendo e realizada investigação adicional na origem. No atual acompanhamento, com base na associação de sintomas neurológicos do sistema nervoso central e puberdade precoce central no sexo feminino, exames subsidiários para investigação etiológica de ambas foram necessários. Tomografia de crânio, revelou depósito anormal de cálcio em núcleos da base e região hipotalâmica bilateralmente. Descartados diagnósticos diferenciais de calcinose em sistema nervoso central, a associação entre depósito de cálcio em núcleos subcorticais e ativação do eixo hormonal pode ser inferida como causalidade. Conclusão: Agora, apresenta-se em acompanhamento com Endocrinologia e Neurologia Pediátrica com controle das crises convulsivas e regressão de caracteres sexuais secundários. A causa mais frequente de PPC no sexo feminino é idiopática, sendo desnecessária a investigação de etiologias de sistema nervoso central. Contudo, quando associados a sintomas e sinais neurológicos avaliados durante a história clínica, se faz necessário a investigação de substrato anatômico para tal. A relação entre doença de Fahr e PPC têm sido pouco relatadas, já que a calcinose de núcleos da base, na maioria das vezes, poupa a região hipotalâmica.

Descritores: Calcinose, Sistema nervoso central, Puberdade precoce 


\section{QUALIDADE DE VIDA EM PACIENTES COM ARTRITE REUMATOIDE}

Caroline Carbonera, Igor Coelho Guerra, Karina Marques Morilha, Laís Teixeira da Cunha Moraes, Taísa Morete da Silva

Categoria: Painel

Introdução: $A$ artrite reumatoide (AR) é uma doença inflamatória crônica que cursa com envolvimento articular e sistêmico. Caso não se realize o tratamento precoce e adequado, ocasionará danos irreversíveis, como a perda da capacidade funcional, diminuição na qualidade de vida (QV) e prejuízos econômicos. Os pacientes reumatoides podem apresentar, além de artrite, fraqueza muscular, instabilidade postural, alterações na marcha e no equilíbrio, diminuição da mobilidade e da capacidade funcional, fadiga, sedentarismo, redução da acuidade visual e síndrome depressiva. $O$ tratamento da AR envolve o uso de drogas modificadoras do curso da doença (DMCDs), analgésicos, anti-inflamatórios não esteroidais e corticosteroides. Além disso, deve-se orientar adequadamente o paciente e seus familiares sobre o diagnóstico e prognóstico, bem como sobre a importância de prática regular de atividade física e, quando necessário, de apoio psicológico. Objetivo: realizar uma revisão da literatura e discutir sobre a QV em pacientes com AR em fase de tratamento. Material e Método: Realizou-se uma revisão sistemática da literatura acerca da QV de pacientes com AR. A pesquisa foi feita nas bases de dados da SBR (Sociedade Brasileira de Reumatologia), PUBMED, SciELO, Google Acadêmico e BVS (Biblioteca Virtual em Saúde). Foram utilizados como descritores de assunto: artrite reumatoide, qualidade de vida e tratamento. Como critérios, foram incluídos artigos de 2000 a 2021, nos idiomas inglês, espanhol e português. Resultados: Atualmente, médicos e terapeutas orientam fortalecer e exercitar músculos e articulações. Exercícios realizados com acompanhamento possuem um excelente resultado na capacidade aeróbica, reduzindo os prejuízos e proporcionando maior independência em tarefas do cotidiano. Ademais, no início do século $\mathrm{XX}$, a doença foi considerada como multifatorial, concluindo-se que os portadores de AR apresentam alterações neuropsicológicas. Conclusão: Evidenciou-se que a AR altera diretamente a QV dos pacientes pelo seu acometimento heterogêneo. Apesar de grande parte dos prejuízos serem físicos, não se pode subestimar as implicações psicológicas, visto que podem interferir no sucesso terapêutico.

Descritores: artrite reumatoide, qualidade de vida, tratamento. 


\section{RAIVA HUMANA NO BRASIL: PERFIL EPIDEMIOLÓGICO DOS CASOS CONFIRMADOS DE 2010 A 2019}

Anessa Tiemi Yoshida, Gabriela da Silva Cruz, Matheus Alexandre da Silva Taliari, Danila Fernanda Rodrigues Frias (orientadora)

Categoria: Painel

Introdução: A raiva é uma zoonose muito importante e bastante comentada ainda na atualidade devido ao grande número de indivíduos expostos ao risco de contágio, o alto custo com ações de prevenção, controlee tratamento humano pós-exposição, e possuir alta taxa de mortalidade. Estes fatores mantém a doença como uma zoonose negligenciada e um sério problema de saúde pública em todo o mundo. Para que medidas de políticas públicas eficazes sejam tomadas por gestores, pesquisas com cunho epidemiológico devem ser realizadas para auxiliar no direcionamento das ações a serem executadas. Objetivo: Desta forma, a presente pesquisa teve por objetivo avaliar o perfil epidemiológico dos casos de raiva humana no Brasil dentre os anos de 2010 a 2019. Metodologia: Realizou-se um estudo transversal, descritivo, retrospectivo e qualiquantitativo com dados secundários coletados de 2010 a 2019 do site TABNET/DATASUS. As informações coletadas foram: número de casos de raiva humana confirmados por estado da federação, zona de residência, faixa etária, escolaridade, raça e sexo. A análise dos dados se deu por meio de estatística descritiva. Resultados: Foram confirmados no período avaliado 37 casos de raiva humana no Brasil, com destaque para o estado do Pará que albergou $27 \%$ dos casos, o Maranhão com 19\%, e o Ceará com 10,8\%. Com relação ao perfil dos indivíduos acometidos, $75,7 \%$ eram do sexo masculino, $81 \%$ da raça parda, 40,5\% possuíam baixa escolaridade (ensino básico) e 37,9\% possuíam entre 20 e 39 anos de idade. A maioria, 64,9\% residiam em área rural, o que pode indicar agravo provocado por animais silvestres, principalmente morcegos. Conclusão: A pesquisa permitiu concluir que os sujeitos acometidos por raiva humana no Brasil possuíam características compatíveis com indivíduos do sexo masculino, economicamente ativos, de baixa escolaridade e que atuam em área rural. Por se tratar de uma zoonose, na maioria das vezes fatal, ações com foco em saúde única, por meio de estudo dos casos em seres humanos, em animais e alterações ambientais, devem ser tomadas visando o controle e prevenção da doença.

Descritores: Lyssavirus, Saúde Única, Zoonose 


\section{RELAÇÃO DA DEPRESSÃO PÓS-PARTO COM O PARTO CESÁREA}

Bruna Alvarenga Costa, Bruno Santiago Barbosa de Souza, Danielly Bezerra Ribeiro, Eloisa Carvalho Duzzi, Karen Sabrina Moreira Benedito, Leandro Teixeira Paranhos Lopes (orientador)

Categoria: Apresentação Oral?

Introdução: A depressão pós parto (DPP) engloba sintomas depressivos que duram mais de 2 semanas após o parto e predominam na maior parte do tempo, interferindo na qualidade de vida da puérpera. A etiologia é multifatorial, todavia, é sabido que as puérperas estão mais suscetíveis a oscilações de humor devido à queda hormonal que ocorre após o fim da gestação, além das mudanças sociais e emocionais do período. É questão de saúde pública, devido sua alta incidência e afetar além das puérperas, os cônjuges e filhos. Objetivo: Analisar se existe relação da depressão pós parto com o parto cesárea. Metodologia: A metodologia empregada é de caráter analítico por meio de uma revisão de literatura bibliográfica. Os dados extraídos na pesquisa foram a partir dos US National Library of Medicine (PubMed) com os descritores: depressão pós parto, fatores de risco e via de parto, de acordo com os Descritores em Ciências da Saúde (DeCS). Para efetuar o cruzamento destes foi utilizado o operador booleano AND. Foram utilizados para a inclusão: artigos, livros e revistas em inglês e/ou português, entre 2017 a 2021, e que estivessem disponíveis na íntegra e para acesso online grátis. Resultado: É inegável a importância obstétrica da cesárea quando bem indicada. Entretanto, os números crescentes do procedimento cirúrgico no país devem-se á cirurgias eletivas, sem indicações médicas, muitas vezes, apenas, em decorrência ao medo do parto vaginal pela mulher. Com isso, o Brasil tornou-se o segundo país do mundo em número de cesarianas, perdendo apenas para Costa Rica. Tanto que a Organização Mundial da Saúde estipula como aceitáveis taxas de $15 \%$ de cesáreas, mas, no Brasil, esse número chega a $45 \%$. Um estudo transversal do Irã descobriu que o DPP foi maior entre as mães submetidas a cesárea $(21,17 \%)$ em comparação com as mães submetidas parto vaginal (8,23\%). Analisando o perfil das mulheres que apresentaram DPP na atenção básica no Brasil, das pacientes acometidas pela doença, $77 \%$ são mulheres cesariadas contra $23 \%$ de parto vaginal, valor idêntico a outra pesquisa realizada na cidade de São Paulo-SP em 2015 e aproximado noutra (65\%) realizada na Universidade Federal do Amazonas em 2019. Conclusão: Conclui-se que a cesariana é fator de risco para depressão pós parto, visto que a incidência da doença é maior nas mulheres submetidas a cesárea. Sugere-se que o ensino médico reforce as vantagens do parto normal, afim de mudar a cultura cesarista do Brasil e reduza os níveis de DPP.

Descritores: Depressão pós parto, fatores de risco, via de parto 


\section{RELAÇÃO DO ÓXIDO NÍTRICO E DOENÇAS CARDIOVASCULARES: UMA REVISÃO DE LITERATURA}

Gabriela de Godoy, Larissa Malvestio Arakaki, Mariana de Godoy, Leda Ferraz (Orientador)

Categoria: Apresentação Oral

Introdução: óxido nítrico é uma molécula vasodilatadora liberada pelo endotélio, apresentando um papel essencial na regulação do sistema cardiovascular, tanto no controle da resistência periférica vascular como no processo de agregação plaquetária, impedindo a formação de trombos e, consequentemente, prevenindo os processos trombóticos e o aparecimento de doenças aterotrombóticas. Porém, deficiências em sua produção ou de sua disponibilidade é a marca registrada de várias doenças, especialmente as doenças cardiovasculares, como a hipertensão arterial sistêmica, aterosclerose, dentre outras. Objetivo: neste contexto, o objetivo desta revisão é analisar a relação entre óxido nítrico e o aparecimento de doenças cardiovasculares. Material e Método: Trata-se de uma pesquisa bibliográfica, do tipo revisão de literatura. Os artigos foram buscados nas bases de dados do Google Acadêmico, Scielo e PubMed, utilizando os descritores: "óxido nítrico", "doenças cardiovasculares", "endotélio vascular", "hipertensão arterial" e "função endotelial". Os critérios de inclusão foram: artigos em inglês, português e espanhol, publicados entre 1994 e 2019. De acordo com os critérios de elegibilidade aplicados, foram utilizados 23 artigos. Resultado: A partir da presente análise, o papel do óxido nítrico no sistema cardiovascular vem sendo enfatizado em todas as áreas médicas e sua ação protetora na pressão arterial, nas doenças tromboembólicas e nas dislipidemias está bem estabelecida na literatura científica. Estas doenças citadas apresentam em sua gênese e/ou em seus mecanismos, alterações na função endotelial. Assim, a disfunção endotelial, caracterizada por menor produção e/ou biodisponibilidade de óxido nítrico, é um dos fatores que contribuem para o aparecimento das doenças cardiovasculares. Conclusão: Diante disso, fica evidente que o papel do óxido nítrico nos sistemas do corpo humano é de extrema importância para ajudar a manter a homeostase, especialmente no sistema cardiovascular, onde a sua redução pode eventualmente ocasionar a aparição de doenças como a hipertensão arterial e a aterosclerose.

Descritores: óxido nítrico, doenças cardiovasculares, endotélio vascular. 


\section{RELAÇÃO ENTRE ALERGIAS NA INFÂNCIA E O CONSUMO DE CORANTES ALIMENTÍ́CIOS.}

Kathlyn Cristina Canedo Póvoa, Renato Machado Porto

Categoria: Painel

Introdução: Corantes são considerados aditivos alimentares, adicionados de forma intencional ou não, apresentando-se principalmente de duas diferentes formas: a sintética (ou artificial) e a natural. O consumo de corantes é grande, principalmente na faixa etária que compreende as crianças e os adolescentes. Objetivo: Investigar e abordar, através de uma revisão integrativa, quais as principais alergias causadas por corantes sintéticos e naturais em crianças, seus principais diagnósticos bem como seus principais tratamentos. Metodologia: Trata-se de um artigo de revisão integrativa, qualitativo e descritivo, que considerou os termos de busca presentes no DeCS/MeSH juntamente com os operadores booleanos (AND ou OR), os seguintes: alergia AND corante(s) OR corantes de alimentos OR hipersensibilidade AND corante(s) OR corantes de alimentos OR Hipersensibilidade Alimentar AND corante(s) OR corantes de alimentos OR alergia a alimentos AND corante(s) OR corantes de alimentos. A revisão foi realizada de 01 de março a 06 de setembro, utilizando-se as bases: Google scholar, PubMed, Lilacs e Scielo, tendo como critérios de inclusão, artigos e publicações que apresentassem data de publicação entre 2016 e 2021, em português ou inglês, que apresentasse algum dos descritores no título ou resumo. Foram considerados como critérios de exclusão, artigos e publicações repetidos, que não apresentavam os descritores previamente definidos no título ou no resumo, que não se apresentavam na íntegra e que não estivessem em português ou inglês. Resultados: Estima-se que nem sempre o consumo de corantes é considerado benéfico. Ainda que haja evidências sobre os seus malefícios, estes produtos são expostos as crianças desde muito cedo, fazendo com que a ingestão diária aceitável (IDA) seja excedida e desrespeitada, podendo apresentar como consequência, as alergias. Recomenda-se que a introdução de alimentos industrializados seja tardia ou evitada, e que, quando da identificação das alergias causadas por estes, seu tratamento seja considerado prioridade e não, desnecessário. Conclusão: Há muito o que ser discutido acerca das alergias causadas por corantes. Órgãos governamentais também precisam estar atentos às atualizações dos guias alimentares vigentes, bem como providenciar guias relacionados a crianças menores de 2 anos. Além disso, precisam estar atentos a fiscalização de embalagens e rótulos de produtos industrializados que consideram este tipo de produto em suas formulações.

Descritores: pigmentos, corantes de alimentos, reação alérgica. 


\section{RELATO DE CASO DE PACIENTE JOVEM DO SEXO MASCULINO DIAGNOSTICADO COM LÚPUS ERITEMATOSO SISTÊMICO}

Ana Paula dos Santos Zuliani, Giovana Barbosa Duarte, lane Tamara Dondé, Ivana Gomes Scarabelo da Costa, Rafael de Brito Nogueira, Vitória dos Santos Zuliani

Categoria: Painel

Introdução: O Lúpus Eritematoso Sistêmico (LES) é uma doença inflamatória crônica de fator autoimune, etiologia não muito conhecida, e pleomórfica. É uma enfermidade mais predominante em mulheres na vida reprodutiva, preferivelmente frequente em pardos e afrodescendentes. Todavia nos homens, pelo fato do Lúpus não se demonstrar tão comum, as manifestações clínicas surgem mais complicadas e com piores prognósticos, como por exemplo a nefrite lúpica. Há também outras apresentações como convulsões, erupção discoide, risco aumentado de doença cardiovascular, serosite e pleurite. Objetivo: Relatar o caso de um paciente do sexo masculino, jovem, diagnosticado com LES (Lúpus Eritematoso Sistêmico). Relato do caso: Homem, 25 anos, com precedente de diabetes mellitus e hipotireoidismo, admitido com manifestações sistêmicas inespecíficas (febre, perda ponderal, anorexia) há 45 dias, além de fotossensibilidade (eritema malar) e aftas orais dolorosas. Nos exames admissionais apresentava anemia hemolítica, com Coombs direto positivo, leucopenia com linfopenia, plaquetopenia e elevação de provas inflamatórias. Na urina havia proteinúria, com eliminação de cerca de $15 \mathrm{~g}$ em $24 \mathrm{~h}$. Foram dosados auto-anticorpos com presença de FAN positivo 1/640 nuclear homogêneo, positividade para Anti-DNA, Anti-SM e Anti-Ro. Notou-se também queda de complemento C3 e C4. Durante a internação, o paciente evoluiu com necessidade temporária de terapia de substituição renal (hemodiálise), devido a LRA (lesão renal aguda), e a biópsia renal demonstrou Nefrite Lúpica Membranosa (Classe V). Iniciado tratamento com Hidroxicloroquina $400 \mathrm{mg} / \mathrm{dia}(4,4 \mathrm{mg} / \mathrm{Kg} / \mathrm{dia})$ e pulsoterapia com Metilprednisolona $1 \mathrm{~g} / \mathrm{dia}$, por $3 \mathrm{dias}$ consecutivos, seguido de prednisona $60 \mathrm{mg} / \mathrm{dia},(0,7 \mathrm{mg} / \mathrm{Kg} / \mathrm{dia})$. Paciente recebeu alta hospitalar, com melhora do quadro, para seguimento ambulatorial. Conclusão: De acordo com o que foi esboçado acima, o Lúpus Eritematoso Sistêmico é uma doença multissistêmica de origem autoimune, majoritariamente feminina, portanto, sugere-se um diagnóstico diferencial em pacientes masculinos. A apresentação clínica é variável e a evolução costuma ser crônica, com períodos de exacerbação e remissão. Nos casos em que há acometimento renal, a realização de biópsia renal se torna necessária para o prognóstico e tratamento, excluindo outras hipóteses diagnósticas.

Descritores: Homem, lúpus eritematoso sistêmico, nefrite lúpica membranosa. 


\section{RELATO DE CASO: PACIENTE COM SEQUELAS POR INTERNAÇÃO PROLONGADA DO COVID-19}

Giovana Barbosa Duarte, Izabella Borges Garcia Gomes, Mylena Aparecida Silva de Camargo, Rafael de Brito Nogueira, Flávio Carlos Ruy Ferreira (orientador)

Categoria: Apresentação Oral

Introdução: No Brasil, o primeiro caso de Coronavírus (Sars-Cov-2) foi registrado em fevereiro de 2020, na cidade de São Paulo. Entre os diversos sintomas causados pelo vírus, destacam-se as síndromes respiratórias agudas, que podem variar de sintomas leves a condições graves, como internação hospitalar, a qual, dependendo da evolução do paciente, pode durar meses gerar diversas consequências ao seu organismo. Objetivo: Relatar o caso clínico de um paciente diagnosticado com Covid-19 e que apresentou diversas sequelas depois de ter ficado muito tempo hospitalizado. Relato de caso: A.A.S, 69 anos, com precedente de doença pulmonar obstrutiva crônica e hipertenso. Faz uso diário de Losartana, AAS, Teolongui, Fomoterol e Sinvastatina. Foi diagnosticado com Covid-19 em agosto de 2020, evoluindo com mal prognóstico. Necessitou de internação por 20 dias na ala de unidade de terapia intensiva, com ajuda de suporte ventilatório (intubação) por um período de 58 dias. Adquiriu uma bactéria resistente de trato urinário, não respondendo mais aos medicamentos. Após quase dois meses, foi extubado, ficando internado por mais 21 dias, acamado e não respondendo a estímulos neurológicos. Conforme sua evolução, obteve alta hospitalar. Depois de dias em casa, começou a apresentar sequelas desse longo período internado, como febre intensa, escaras em região sacral com lesão por pressão de média extensão, grande área de tecido necrótico, pés equinos, não se alimentava e nem se hidratava, vômitos, alteração nefrítica e infecções do trato urinário recorrentes. Foi encaminhado para o CADIP, iniciando o seu tratamento com medicação: antibióticos (Ceftriaxona $1 \mathrm{~g}-2$ ampolas endovenosa 1x/dia, por um período de 3 dias consecutivos), antiemético antes de cada refeição, sinvastatina $40 \mathrm{~g}$. AAS $100 \mathrm{~g}$, losartana $50 \mathrm{~g} 2 \mathrm{x} / \mathrm{dia}$, ingestão hídrica de pelo menos 21 por dia e tratamentos no centro de reabilitação Lucy Motoro, como fisioterapia, atendimento psicológico, fonoaudiológico e terapia ocupacional. Após seis meses de tratamento, seu quadro apresentou boa evolução, mas continua em manutenção. Conclusão: Esse caso mostra que o coronavírus pode ser muito grave, gerando meses de internação e diversas consequências à saúde do paciente, não se restringindo ao sistema respiratório, há diversos outros desdobramentos causados pelo tempo de internação. Sendo assim, em busca de uma recuperação completa, mostra-se necessário um acompanhamento multidisciplinar das áreas relacionadas à saúde.

Descritores: Internação, sequelas, Coronavírus. 


\section{RESSONÂNCIA MAGNÉTICA NA CARDIOMIOPATIA ISQUÊMICA}

Étore Scapin Baroni, Henrique César Scapin Ximenes, Jozyane Ribeiro Fuginami Gotto, Juliana da Cruz Nunes Silva, Mariana Caroline Carocia, Nathália Regina Gasparelli Herrero Zinezi Rodrigues

Categoria: Painel

Introdução: A cardiomiopatia isquêmica está entre as patologias miocárdicas com mais alta de morbimortalidade, caracterizada pela presença de isquemia do miocárdio associada ou não a fibrose causada pelo infarto miocárdico. Ocorre quando há desequilíbrio na distribuição de oxigênio e diminuição do fluxo sanguíneo. No diagnóstico, dentre os exames não invasivos, os mais utilizados são a ressonância magnética cardíaca e a tomografia computadorizada cardíaca, sendo que através da RNM se tem a compreensão mais detalhada da anatomia, função e perfusão miocárdica, caracterização tecidual e viabilidade cardíaca. Objetivo: Este trabalho tem como objetivo revisar a literatura cientifica em relação à Ressonância Magnética na cardiomiopatia isquêmica. Metodologia: A metodologia empregada é de caráter analítico por meio de uma revisão de literatura bibliográfica. Os dados extraídos na pesquisa foram a partir dos US National Library of Medicine (PubMed) com os descritores: Magnetic Resonance Imaging e Cardiomyopathy, de acordo com os Descritores em Ciências da Saúde (DeCS). Foram encontrados 8.738 artigos e após critérios de inclusão e exclusão, 18 artigos foram utilizados. Os utilizados para a inclusão: artigos em inglês, português ou espanhol, entre junho de 2015 a julho de 2021. Excluíram-se, os estudos que não abordassem o conceito relevante para o alcance do objetivo. Resultado: Segundo Paulo R. Schvartzman, em seu artigo: Ressonância Magnética na Avaliação da Cardiopatia Isquêmica, a RNM é utilizada de forma rotineira e sequencial em que a duração dessa avaliação não excede 30 minutos afim de estimar a função ventricular, detecção de isquemia e viabilidade do miocárdio. Em contrapartida, Fernanda Boldrini Assunção, em seu artigo: Ressonância magnética cardíaca e tomografia computadorizada na cardiomiopatia isquêmica: atualidades, afirma que a utilização da RNM possui algumas contraindicações relativas, tais como: pacientes portadores de marca passo, de desfibriladores implantados, de clipes cerebrais, entre outros. Conclusão: A RNM no diagnóstico da cardiomiopatia isquêmica possui alta sensibilidade e alta especificidade, possuindo contraindicações e efeitos adversos reduzidos. É considerada um dos principais exames para diagnóstico por imagem, podendo ser realizado na fase aguda ou crônica, alcançando um padrão de referência para avaliação da função global e regional miocárdica com extrema importância para auxílio do médico nos diagnósticos dos seus pacientes.

Descritores: Ressonância Magnética; Cardiomiopatia 


\section{SEPSE EM TEMPOS DE COVID-19}

Amanda Spaziani, Giovana Maschietto Sussai, Micaelly Silva de Camargo, Mylena Aparecida Silva de Camargo, Natália Inácio Beltramini, Raissa Frota

Categoria: Painel

Introdução: O SARS-CoV-2 é uma síndrome respiratória aguda grave de caráter pandêmico com alta taxa de transmissibilidade, a doença é chamada de COVID-19. A sintomatologia é parecida com a da gripe, mas evolui de maneira diferente com infecção leve, grave ou estado crítico evoluindo com SARS (Síndrome respiratória aguda grave). Sendo a sepse uma disfunção do organismo frente a ação desequilibrada do sistema imune à uma infecção, que eleva a mortalidade do paciente com esse quadro. Objetivos: Tem como objetivo realizar uma revisão de literatura a respeito da sepse em tempos de COVID-19. Métodos: Este trabalho é uma revisão de literatura na base de dado PubMed (US Nationall Library of Medicine) fazendo uso dos descritores: "sepse", "covid-19" e "sars-cov-2" com o operador booleano "AND". Foram encontrados 303 artigos e após análise com critérios de exclusão e inclusão, foram selecionados 10 estudos. Os critérios de inclusão utilizados foram: artigos em inglês, do ano de 2020, que estivessem disponíveis para acesso online e gratuito. $\mathrm{E}$ o critério de exclusão foi: artigos que não abordassem o objetivo deste trabalho. Resultados: As sepses na covid19 quando investigadas nem todas foram bacterianas, e sim o próprio coronavírus como causador, principalmente em indivíduos com doença de base como: diabetes, hipertensão e doença coronariana, se agravando ainda com o aumento da idade, através da exacerbação na ativação de macrófagos, acarretando uma hiperinflamação, gerando uma depleção de linfócitos (LÓPEZCOLLAZO,\&nbsp;et al., 2020). Esses fatores demonstraram a falência de múltiplos órgãos por causar uma maior ativação da cascata de coagulação, causando trombose da microcirculação, com isso, o tratamento com anticoagulantes se faz necessário. Alguns genes desse vírus demonstraram uma sinalização negativa na mitocôndria para organização, respiração e autofagia, explicando o motivo da desorganização mitocondrial aumentar a gravidade da sepse na covid-19 (SHENOY, 2020). Conclusão: Conclui-se que a sepse induzida pelo SARS-Cov-2 está relacionada ao desequilíbrio mitocondrial e ao aumento de citocinas inflamatórias levando a uma hiperinflamação e supressão exacerbada, mesmo diante desses conhecimentos, o ambiente a ser estudado ainda é vasto e a abordagem terapêutica pouco conhecida. Com isso, é preciso adoção de estudos e medidas rápidas nos pacientes com a covid-19, principalmente aqueles com fatores de risco para sepse, tendo assim uma melhor expectativa de vida.

Descritores: Sepse, Covid-19, Sars-CoV-2. 


\section{SÍFILIS CONGÊNITA: UMA REVISÃO DA LITERATURA}

Filipe Camargo Mangerona, Marcelo Andrade Ferreira

Categoria: Painel

Introdução: A sífilis congênita é uma Infecção Sexualmente Transmissível, listada como uma das doenças de notificação compulsória no Brasil desde 1986(SINAN), é causada pela disseminação hematológica por via transplacentária do Treponema pallidum em gestantes infectadas ou inadequadamente tratadas para o feto. A transmissão vertical pode ocorrer em qualquer fase da gestação e qualquer estágio da doença, sendo que na fase primaria e secundaria a taxa de infecção é de 70 a $100 \%$ e a fases tardias a taxa é de 30\%. Manifestações clinicas mais associadas são: abortamento espontâneo, natimorto, óbitos fetais e manifestações tardias como déficits neurológicos, cognitivos, motoras, visuais e auditivas. Apesar de seu rastreamento ser parte dos exames iniciais de pré-natal, e de responsabilidade da atenção básica, com diagnóstico sensível e tratamento eficaz e de baixo custo, o número de casos notificados apresenta um aumento significativo, representando um grave problema de saúde pública. Objetivo: Esse trabalho tem como objetivo a busca das principais literaturas recentes, acerca da sífilis congênita devido sua importância e relevância para a saúde pública. Materiais e métodos: Esse estudo se trata de uma revisão de literatura, baseado nos artigos encontradas na base de dados Scielo e BVS, selecionados por meio do descritor sífilis congênita e incidência. Foram selecionados 9 artigos compreendidos no período de 2009 à 2019. Resultados: Após a análise, dados dos últimos 10 anos evidenciam um aumento no número de casos no Brasil, em 2009 a taxa era de 2,1 casos/1.000 nascidos vivos, e em 2019 8,2 casos/1.000 nascidos vivos, com taxa de mortalidade de 5,9/100.000 nascidos vivos. Esse aumento se deve a alguns fatores como a elevação da testagem, a diminuição no uso de preservativos, à redução na administração da penicilina nos serviços de atenção primária à saúde e ao desabastecimento mundial do medicamento. Conclusão: Diante do exposto evidencia-se uma falha no combate à sífilis congênita no Brasil, permanecendo um desafio ao Sistema Único de Saúde, sobretudo ao observar o seu aumento ao longo dos anos e por considerar que a ocorrência da sífilis congênita indica fragilidades na atenção ao pré-natal, sendo, um indicador de alerta para elaboração de planos de saúde mais eficazes, devido sua gravidade e potenciais manifestações incapacitantes.

Descritores: sífilis congênita, incidência 


\section{ULTRASSOM PULMONAR NA DETECÇÃO PRECOCE DA SÍNDROME DO DESCONFORTO RESPIRATÓRIO DO RECÉM-NASCIDO}

Étore Scapin Baroni, José Miguel de Souza Maia, Jozyane Ribeiro Fuginami Gotto, Juliana da Cruz Nunes Silva, Mariana Caroline Carocia, Henrique Cesár Scapin Ximenes (orientador)

Categoria: Apresentação Oral

Introdução: A Síndrome do desconforto respiratório do recém-nascido (NRDS) é caracterizada pela imaturidade pulmonar fisiológica e estrutural, devido a deficiência de surfactante pulmonar ao nascer, tornando os alvéolos mais propensos ao colapso no final da expiração. É mais comum em recémnascidos prematuros, porém bebês nascidos de parto cesariano apresentam riscos aumentados em morbidades respiratórias neonatais, incluindo a NRDS. O ultrassom pulmonar (LUS) vem sendo utilizado para este diagnóstico, por sem uma técnica não invasiva e não radioativa comparada a radiografia torácica (CXR), que era o principal meio de diagnóstico da NRDS. Objetivo: Este trabalho tem como objetivo revisar a literatura cientifica em relação à Radiologia em Unidade de Cuidados Intensivos Neonatal. Metodologia: A metodologia empregada é de caráter analítico por meio de uma revisão de literatura bibliográfica. Os dados extraídos na pesquisa foram a partir dos US National Library of Medicine (PubMed) com os descritores: Radiology e Intensive Care Units, Neonatal, de acordo com os Descritores em Ciências da Saúde (DeCS). Para efetuar o cruzamento destes foi utilizado o operador booleano AND. Foram encontrados 403 artigos e após critérios de inclusão e exclusão, 16 artigos foram utilizados. Os utilizados para a inclusão: artigos em inglês, português ou espanhol, entre junho de 2015 a julho de 2021, e que estivessem disponíveis na íntegra e para acesso online grátis. Excluíram-se, os estudos que não abordassem o conceito relevante para o alcance do objetivo; estudos repetidos; segundo critérios de qualidade metodológica. Resultados: Estudos realizados verificam a confiabilidade da utilização de LUS precoce para a admissão na UTIN. Fora analisada a especificidade e sensibilidade, demonstrando que o LUS apresenta uma alta sensibilidade (99\%) e especificidade (95\%) em comparação ao CXR, $88,23 \%$ e $89,53 \%$ respectivamente. Ficou demonstrado também que o aspecto do ultrassom do "pulmão branco" e a ausência de "áreas poupadas" tem sensibilidade e especificidade de 100\%. Conclusão: Portanto, o LUS tem sido recomendado na detecção precoce de pacientes com NRDS, e em diversos outros procedimentos de rotina na UTIN, devido ao fato de o CXR ter um alto efeito nocivo aos bebês que são mais sensíveis à radiação. Entretanto, há poucos estudos sobre o assunto sendo necessário mais estudos para se avaliar melhor o desempenho da LUS no diagnóstico do NRDS.

Descritores: radiologia, unidade de terapia intensiva neonatal. 